\title{
What's so spatial about diversification in Nigeria?
}

\begin{abstract}
Many households in developing countries allocate their productive assets among various income generating activities in order to develop a portfolio of income from occupations with different degrees of risk, expected returns and seasonal and liquidity constraints. The push and pull factors influencing diversification decisions of households are widely discussed in the literature; however, no study to date has taken into account spatial interdependence of household decisions in spite of various channels of neighborhood effects such as information flow, learning from others, social networks and agglomeration economies. This paper fills in the gap by incorporating spatial dependence in the choice model of diversification by using a spatial auto-regressive probit model and an advanced Bayesian strategy to its estimation.

Empirical analysis is run taking advantage of the Nigerian General Household Survey Panel, 2010-2011 providing GIS coordinates for the surveyed households. The results imply endogeneity of the neighbors' decisions to allocate their productive assets among various occupations and signal the importance of social learning and agglomeration effects favoring the spillover of diversification activities through neighbors' networks and local markets. The households' decisions respond to local environment factors such as weather shocks or infrastructural constraints. As shown by the regional differences, taking into account spatial interdependence is particularly important in the event of a wide divide of the data available into different zones, as for example in case of the Nigerian northern region where the states are larger.
\end{abstract}

(C) 2017. This manuscript version is made available under the Elsevier user license http://www.elsevier.com/open-access/userlicense/1.0/ 


\section{Acknowledgments}

We gratefully acknowledge cooperation of the LSMS team at the World Bank and Nigerian National Bureau of Statistics.

Grateful acknowledgment to four anonymous referees for valuable comments; to Fernando Sedano for assistance with mapping and James Rushing for editorial help.

Computing resources used for this work are provided by the American University High Performance Computing System, which is funded in part by the National Science Foundation (BCS-1039497); see www.american.edu/cas/hpc for information on the system and its uses.

This research did not receive any specific grant from funding agencies in the public, commercial, or not-for-profit sectors. 


\title{
What's so spatial about diversification in Nigeria?
}

\begin{abstract}
Many households in developing countries allocate their productive assets among various income generating activities in order to develop a portfolio of income from occupations with different degrees of risk, expected returns and seasonal and liquidity constraints. The push and pull factors influencing diversification decisions of households are widely discussed in the literature; however, no study to date has taken into account spatial interdependence of household decisions in spite of various channels of neighborhood effects such as information flow, learning from others, social networks and agglomeration economies. This paper fills in the gap by incorporating spatial dependence in the choice model of diversification by using a spatial auto-regressive probit model and an advanced Bayesian strategy to its estimation.

Empirical analysis is run taking advantage of the Nigerian General Household Survey Panel, 2010-2011 providing GIS coordinates for the surveyed households. The results imply endogeneity of the neighbors' decisions to allocate their productive assets among various occupations and signal the importance of social learning and agglomeration effects favoring the spillover of diversification activities through neighbors' networks and local markets. The households' decisions respond to local environment factors such as weather shocks or infrastructural constraints. As shown by the regional differences, taking into account spatial interdependence is particularly important in the event of a wide divide of the data available into different zones, as for example in case of the Nigerian northern region where the states are larger.
\end{abstract}

Keywords: Income diversification in developing countries; Spatial econometrics 


\section{Introduction}

The importance of income diversification in developing economies is increasingly being recognized (Barrett et al. 2001b; Davis et al., 2009). The diversification practice is frequent among African farmers and consists of engaging into various income generating activities differentiated by returns, degrees of risk and constraints. Many studies report various positive effects of diversification and consider it as a poverty reduction practice: non-farm income positively affects farm production and expenditures on inputs (Babatunde, 2013; Davis et al., 2009; Oseni and Winters, 2009), as well as nutritional outcomes and child anthropometric measures (Babatunde and Qaim, 2010).

A large body of the diversification literature has been developed over 1990-2000s. The literature of the early 2000's conceptualized diversification practice by suggesting several diversification measures and framing diversification incentives commonly classified as push and pull factors (Barrett et al., 2001b and Reardon et al., 2007). It gave rise to a large body of empirical literature using various data sets to analyze the determinants of the household's choice and capacity to diversify (some examples are Barrett et al., 2005; Corral and Reardon, 2001; De Janvry et al., 2005; Escobal, 2001; Lanjouw, 2001; Liu and Lan, 2015; Senadza, 2012; Weldegebriel et al., 2015).

Despite the large literature developed, no study to date has taken into account spatial dependence or the 'neighborhood effect': the literature have been focusing on the effects of demographic characteristics and households' and communities' assets. Yet, spatial dependence relates to both push and pull factors driving households toward diversifying activities and can play a considerable role in the household's diversification outcome via information flow, social networks and agglomeration economy effects. Thus, studies to date are potentially missing a critical aspect of the household's decision process. Moreover, ignoring spatial relations may lead to biased or inconsistent estimates of the effects relating to various observed determinants of diversification choice. This paper fills in the gap by extending the literature on the determinants of diversification among farming households through incorporating spatial dependence in the choice model. Explicitly, the 
paper seeks to answer whether or not diversification among farming households is linked to the decisions of neighboring households.

The contribution of the paper is multifaceted. From the economic perspective, we add to the literature by modeling the neighborhood effect relating to numerous diversification factors exhibiting spatial dependence. The overall methodology is beyond the methods traditionally used not only in the literature on income diversification but more broadly in the literature applying discrete choice models to the household decision making in developing economies. Indeed, empirical analysis allowing for spatial interdependence is mostly adopted by regional sciences, real-estate, geographical and transportation economics. In agricultural economics, it is mainly advanced on the topics of land use and land markets (Brady and Irwin, 2011; Breustedt and Habermann, 2011; Holloway et al., 2007), and spatial distribution of agricultural production and practices (Holloway asund Lapar, 2007; Schmidtner et al., 2012). Yet, despite an appealing context of developing economies, empirical studies using spatial econometrics at household level and applied to developing economies remain scarce and confined to land use (De Pinto and Nelson, 2007) and precision agriculture (Nelson, 2002).

From the empirical perspective, we use an innovative approach when studying the decision to diversify. It consists of applying a Spatial Auto-regressive Probit model which allows us to incorporate the spatial interdependence in the choice model and an advanced Bayesian estimation strategy offered by LeSage and Pace (2009). The methodology used allows for efficient empirical implementation of the spatial dependence of the binary outcomes related to different agents.

The empirical analysis is run using the first wave of the Nigerian General Household Survey Panel (GHS-Panel), 2010-2011. The GHS-Panel is an ongoing survey with the first two waves published by the time of the present study. Crucially for our study, the data contain GIS coordinates for the surveyed households ${ }^{1}$ which allows us to define a spatial network and to expand the empirical model to incorporate spatial dependence between diversification outcomes of different households. Nigeria represents a good case study for 
examining the spatial nature of rural non-farm activities not only because of GIS data availability at the household level, but also because of wide diffusion of diversification in the country: according to the GHS-Panel (2010/2011), about 60 percent of Nigerian farming households diversify with non-farm enterprise being the most popular activity. Statistically balanced subsamples of diversifying and non-diversifying households along with spatial variation are advantageous in terms of data variation and model identification. Finally, since agricultural employment in Nigeria accounts for about 60 percent of the working population with two-thirds of the total agricultural production provided by traditional smallholders that use basic technologies, the Nigerian case is instructive in terms of the behavior of farming households in the framework of a developing economy with a strong rural component.

The paper is organized as follows. Section 2 introduces the main concepts of the analysis. Sections 3 and 4 outline the country background and specify the data respectively. Section 5 outlines the spatial auto-regressive probit model and its outcomes (the main steps of the Bayesian estimation approach and the simulation technique used for its empirical application are provided in Appendix A). Section 6 presents national-level and regional results. Section 7 summarizes findings and concludes in terms of the policy implications perspective.

\section{Conceptual Framework}

\subsection{Concepts}

Diversification incentives. The literature (see Barrett et al. 2001b; Davis et al., 2009) suggests that there are two kinds of factors at play when an agent decides to diversify: "push" and "pull" factors.

Push factors relate to needs and income desperation of the farming household, and/or market imperfections that farming households face. These factors include risk associ- 
ated with uncertainty about agricultural outcomes and related consumption shocks, low marginal productivity of labor on the farm and liquidity constraints. For example, Babatunde (2012) and Oseni and Winters (2009) show that off-farm² income may relax liquidity constraints for farming households. They also suggest that off-farm income may have positive spillovers to agricultural production. Using Nigerian data, Oseni and Winters (2009) find that non-farm income has a positive effect on expenditures for inputs while Babatunde (2012) finds that participation in off-farm activities complements own agricultural production.

Pull factors relate to local factors that create a positive environment for diversification and attract households towards diversification. Their components are strategic complementarities between activities and comparative advantage drawn from diversification (Barrett et al., 2001b); households may be pulled towards diversifying by higher returns provided by various activities (Escobal, 2001). Pull factors might be effective in the areas of economic growth and highly developed infrastructure: growing agricultural zones or a sector development such as mining or tourism can generate demand for non-farm goods, services and stimulate development of the rural non-farm sector with higher wages. Developed infrastructure is a strong pull factor since it induces lower transport and transaction costs raising households' profits from off-farm activities and opens additional non-farm and/or cash cropping options representing comparative advantages for farming households.

Barriers to entry. When engaging into diversified activities, households face strong uncertainty about the returns. Indeed, it is possible that there is no positive effect on income. The push factors could lead a household towards low return activities (Barrett et al., 2005) resulting in a negative effect on agricultural production if the lost farm labor outweighs the benefit from investment in diversified activities. Risk aversion might therefore discourage engagement into diversification activity.

Not only profit maximization is uncertain under the diversification choice, but also entry into diversified activities might be uncertain or unavailable to many (Barrett et al., 2001a; De Janvry et al., 2005). Indeed, off-farm entrepreneurship and job, as well as cash crop 
adoption, require some human, social, financial, and infrastructural capital. This implies that there may be barriers at the household and community level for households with no endowments and assets.

\subsection{Incentives and capacity variables}

The above discussion translates into a set of variables commonly available from household and community data, and traditionally employed as explanatory variables of the diversification process among the households. The variables relate to push and pull incentives as well as the capacity to access diversification activities.

Household landholding is one of the important diversification determinant associated with both incentive factors and the capacity to diversify. On the one hand, a small farm size is a push factor inducing households to complement their earnings and food necessities by seeking diversification (Reardon et al., 2007), while large farmland is associated with greater opportunity costs of undertaking activities outside of the household farm reducing their comparative advantages for larger landholders. On the other hand, land can enable rental income in the event of a functioning credit market empowering households with financial capital and increasing their capacity to overcome barriers to entry and undertake a higher return off-farm activity; in this case, acreage can be positively correlated with diversification. Larger landholding can also favor cash crop adoption (Goldstein et al., 2013). Further, in the presence of functioning land markets, land can be sold to gain financial capital or on the contrary acquired along with other agricultural assets using capital gained from diversification. Reverse causality can therefore contribute to both positive and negative association between landholding and diversification.

Empirical evidence provided in the literature diverges considerably. Corral and Reardon (2001) and Liu and Lan (2015) report a negative link between acreage and diversification in Nicaragua and China and prevail hypothesis of the incentive nature of small land size pushing subsistence farmers to diversify their income; Abdulai and Deldago (1999) 
and Weldegebriel et al. (2015) find no effects in Ghana and Ethiopia while Abdulai and Crole-Rees (2001) and Djurfeldt (2012) find a positive association in several sub-Saharan African countries. Given the complexity of the mechanisms involved (Reardon et al., 2007), empirical disagreement might be related to different prevailing mechanism in one country as compared to another.

Weather shocks, in particular rainfall instability, is a strong push factor that can be controlled empirically. Rainfall shortage induces sharp downturns in agricultural production pushing households to seek any kind of employment in the non-farm sector leading the poor to engage in low-return jobs (Reardon et al., 2007). A positive link between unfavorable agro-climatic conditions and diversification is documented in previous empirical literature (Barrett et al., 2005).

Infrastructural constraints relating to availability of roads, electricity, water and other public goods, represent the pull factors improving off-farm earning opportunities and cash crop market access. Their relevance as strong diversification determinants is confirmed by empirical studies using community data from different countries (Barrett et al., 2001b; Senadza, 2012; Winters et al., 2009). Weakly developed infrastructure may be on the other hand an entry barrier for rural households.

Human capital is a commonly reported determinant relating to the capacity to overcome entry barriers into diversification activities. Specifically, higher-return employment or self-employment and cash crop adoption are associated with higher educational achievement; uneducated farmers face more severe barriers and limited diversification options such as lower paying casual jobs. Educational achievement is typically captured by the household head's years of education (Liu and Lan, 2015) representing the household human resources on the one hand and eventually relating to educational achievement of the main decision maker on the other. We follow the literature by adopting the same approach: the variable is progressively correlated with the shares of the household members with different levels of education ranging from primary to more than secondary ${ }^{3}$. A positive effect of education is documented by aforementioned empirical studies of Liu and 
Lan (2015), Corral and Reardon (2001), Abdulai and Deldago (1999) and other studies on Uganda (Canagarajah et al., 2001), Ethiopia (Woldenhanna and Oskam, 2001), Ghana (Senadza, 2012) and Nigeria (Babatunde and Qaim, 2009).

Other dimensions of human capital typically addressed by empirical literature are household composition and head's age. The age is associated with capital accumulation such as broader experience expected to favor diversification (though may also be related to risk aversion); the greater size of the household is associated with surplus household labor pushing the household to diversify its income-generating activities (Abdulai and Crole-Rees, 2001).

Spatial dependence. Spatial dependence of diversification practices relates to both push and pull factors driving households toward diversifying activities as well as the capacity to overcome barriers to entry. Indeed, information flow and learning from others might influence household decisions by reducing uncertainty and framing behavioral patterns. Specifically, the importance of interdependence of farming household attitudes towards adoption of new practices has been documented by sociological literature and descriptive studies for a long time (for a review of the literature, see Case, 1992).

Next, interactions with others develop social networks through which farming households might be more likely to engage in diversifying activities. Araujo (2003) points out that individuals usually report referrals from relatives or social networks as a source for finding off-farm jobs. The household's social capital also plays a role. Households would not risk venturing into an activity if they do not have relationships which could help reduce transaction costs, or provide a safety net in case of need (Fafchamps and Minten, 1998). Barrett et al. (2001b) suggest that lower diversification reported among women more frequently working at home and immigrants to a community might be due to lack of social ties. Spatial dependence, consequently, relates to tackling entry barriers to diversification as well as potential insurance.

Furthermore, the factors linked to agglomeration economies ${ }^{4}$ might influence the household's decision to diversify. Through agglomeration effects the household may reduce 
costs and therefore maximize its profits. For example, farmers may decide to diversify because their neighbors' activities reduce the transaction costs of participating: e.g., the transportation cost is reduced at the agglomeration level (Glaeser, 2010). Neighbors may already be securing inputs or selling output so the cost to entry for a new farm household might be lower due to the neighbors' participation.

\subsection{Diversification definitions}

The literature on income diversification of farming households suggests several ways of addressing the issue empirically. The standard practices consist of relying on the household's asset allocation, income diversification, and labor supply in diverse income generating activities (Barrett et al., 2001b). Income diversification has been a prevailing approach; it is based on the number of income sources which is often extended by their shares over the total income (Barrett et al., 2001b; Liu and Lan, 2015). The approach is efficient to quantify the extent of diversification.

Since our analysis focuses on the spillover effects discussed in the previous subsection, our main interest relates to the decision component of the diversification practice, its incentives and accessibility rather than its extent. We follow therefore Corral and Reardon (2001) and Abdulai and Crole-Rees (2001) by adopting the labor supply approach and exploring the likelihood of households' engagement into diversification activities different from subsistence farming. Since some households may adopt multiple diversification activities, a set of indicators is adopted: the broadest one defines diversification by positive labor supply of households in any diversifying activities. Since activities might be different in its nature, the analysis is extended by refining the definition in several ways.

First, we focus on sectoral assignment by defining diversification as the household's engagement into a non-farm activity which can be non-farm enterprise or non-farm wage employment. Second, we define diversification as a household's engagement in any farm activity different from subsistence farming, that is farm wage employment or cash crop 
adoption. Finally, we use a frequency approach by defining diversification as non-farm entrepreneurship which is the most frequent way of diversification among rural households (Barrett et al., 2001b) in Africa and in Nigeria in particular, or as cash crop adoption which is also a relatively frequent practice in Nigeria (Table 1) and an expanding practice in African rural economies.

\section{Country Background}

Nigeria is Africa's most populous nation, with over 160 million inhabitants (Oseni et al., 2015). It is commonly divided into two major regions, North and South. The North and South of the country differ considerably. Figure 1 provided by Bloch et al. (2015) and reporting the spread of cities of different size across the country, shows that the majority of larger cities are located in the South of the country; this is historically due to the South's proximity to the coast which has been benefiting its stronger development as compared to the North (Bloch et al., 2015). Despite extensive spatial expansion of two northern urban fields, unequal development of the South and North still persists (Corral et al., 2015) which might be related to industrial regional specialization and oil industry concentration in the South as illustrated by Figures 2 and 3 (Appendix B). The North and South also have considerable agro-ecological differences and consequent agricultural specialization: the North suffers from more drastic climate variations because it is partly covered by the Sudan-Sahel ecological zone (Ekpoh \& Nsa, 2011); its agricultural output is mainly peanuts and cotton while southern output is oil palm, cocoa and rubber.

Agriculture is the main source of employment for the population. Close to 60 percent of the country's population relies on it for their livelihoods (Oseni and Winters, 2009). Agriculture alone can not sustain and provide sufficient income for the consumption needs of the Nigerian farming household: sixty percent of farming households diversify their income activities. 


\section{Data}

The analysis is done using the Nigeria General Household Survey (GHS) conducted by the National Bureau of Statistics in 2010-2011. The observational units of this analysis are Nigerian farming households, which are 2,727 out of the $5000^{5}$. We exploit the first out of two available waves of the survey due to the GIS data access at the household level of this wave and an $18 \%$ attrition rate among the farming households in our sample due to households' dropping from farming and/or changing location with also few households missing from the survey or not providing the full information needed.

Table 1 displays the percentage of households involved in the different diversification activities considered, for the whole country, the North, and the South. Farming households mostly diversify into non-farm enterprises (NFE). It is an important supplementary source of income for Nigerian households despite the low productivity of non-farm enterprises and weak growth, which is insufficient to hire employees from outside the household (Haggblade, 2007). Few farming households engage in farm wage labor outside the household's farm. Wage work (public or private) is also scarce with about 10 percent of households having a member employed for wage. Finally, close to 14 percent of farming households plant commercial crops.

\section{Table 1 HERE}

Table 2 presents the summary statistics for the chosen variables. Households who diversify have significantly less land than those who do not. Diversifying households on average have younger and more educated heads and significantly more members. Households who do not diversify on average face more infrastructural constraints than those who diversify. The rainfall shock in the year before the household makes the decision to plant have the same unconditional means in two groups. Following Miguel et al. (2004), it is measured as the percentage of rainfall increase experienced by the household the year before planting decisions $^{6},\left(R_{i t}-R_{i t-1}\right) / R_{i t-1}$.

Table 2 HERE 


\subsection{Diversification by space}

The spread of the sampled households by their diversification status is shown in Figure 4. The blue dots represent the diversifying households. The map shows that the population density is higher in the South of the country than in the North. Omnipresent spread of diversified households is driven by non-farm diversification, non-farm entrepreneurship more specifically, non-farm wage diversification being scarce (Figure 5). Farm diversification -essentially cash cropping- takes place mainly in the South with some households planting cash crop in the central North (Figure 6).

To explore statistically spatial distribution of the diversification practice, we first investigate spatial autocorrelation of the key binary variables using local indicator of spatial association (LISA) advanced by Anselin (1995). Figures 7 and 8-9 show maps built from the resulting local Moran's I indicators: the blue and red points correspond to locations with high spatial association of diversification outcomes; specifically, red points indicate clusters of diversifying households and blue points indicate those of non-diversifying households.

Investigation of Figures 1 and 7 implies that diversification clusters in the areas of the biggest population centers meaning more factors that "pull" households towards diversification and away from agriculture. While non-farm diversification clusters stronger in the South-west and central North and farm diversification does heavier in the South, the pattern holds for both, non-farm and farm diversification: the areas close to large urban and population centers might provide a favorable environment for non-farm entrepreneurship as well as large output markets for cash crops, particularly for the farming outputs which are easily perishable yet monetarily more rewarding.

Such a framework implies the possibility of a double channel for spatial effects: one might be a 'common exposure' effect relating to similar responses of the households to the similar pull factors spatially associated and depending on the distance from the population centers; another one is a 'contagion' effect relating to the spatial dependence 
as conceptualized in section 2.2, that is through information flow between neighboring farming households and their local social networks. Discrimination between 'common exposure' and 'contagion' effects is a challenging task. While there are some tests offered in the literature on the continuous dependent outcome, it is not yet set up in the context of the discrete choice variable (Franzese and Hays, 2014). Fortunately, the data allow to control for 'common exposure' by employing urban/rural community qualification, the country states and most importantly an infrastructural index: the infrastructural variable we use is constructed using principal-component analysis (Filmer and Pritchett, 2001) and builds on distances from households' locations to road, market, population centers, and the border ${ }^{7}$. The infrastructural index is highly spatially correlated: the global Moran's indicator is strong $(I=0.91)$ and highly statistically significant ( $p$-value $<<0.01)$. The local indicators of spatial association reported in Figure 10 emphasize further spatial association of infrastructural constraints as well as the regional divide of the country: strong infrastructural constrains (red points) are spatially clustered in the North while weak ones (deep blue points) are clustered in the South. Finally, a rainfall shock variable available for the analysis and representing an important push factor, is also highly spatially correlated: Moran's $I=0.93$ with $p$-value $<<0.01$.

We next apply the spatial autoregressive model (see Section 5) to test for the spillover ('contagion') effects among farming households relative to their income diversification behavior.

\section{Spatial Diversification Model}

This section traces out the spatial diversification model along with its outcomes. The estimation is done using a Bayesian approach which is non standard in the applied empirical literature in development and agricultural economics and specific to the estimation of the spatial autoregressive probit model used. Its main steps are outlined in Appendix A. 
Unlike the majority of studies involving continuous outcomes, application of discrete choice models that allow for spatial interdependence of the outcomes did not progress till the late 1990s - early 2000s due to the multidimensional integration required by such models. Among the early studies introducing spatial dependence in a discrete-choice model of households' decisions in developing economies was the work of Case (1992) who used a limited form of spatial dependence allowing for the derivation of a tractable likelihood function associated with the probability of adoption a new harvesting tool in rice farming in Indonesia. Several methods have been developed since to overcome the problem of evaluating a high-dimensional integral ${ }^{8}$. Among approaches relying on classical inference and having fostered some applications of binary probit models are an ExpectationMaximization (EM) proposed by McMillen (1992), a GHK simulator (otherwise referred as a recursive importance sampling, RIS) proposed by Beron and Vijverberg (2004) and generalized methods of moments (GMM) offered first by Pinske and Slade (Pinkse \& Slade, 1998) and linearized next by Klier and McMillen (2008). Depending on the estimator, the tractability of spatial interdependence in a probit setting comes at different costs: the EM and Pinske and Slade's GMM require inversion of a highly-dimensional matrix; the EM also needs parameterization of the spatial heteroscedasticity; the EM and Klier and McMillen's GMM do not provide a standard error for the key parameter of spatial diffusion.

The Bayesian inference method used in our study and dominating the most recent applied literature is an alternative to the aforementioned methods. It overcomes the limitations of the methods based on classical inference and provides whole the distribution of the estimates. Moreover, the Monte Carlo study of Calabrese and Elkink (2014) shows that Bayesian MCMC (Markov Chain Monte Carlo, referred also as Gibbs sampler indicating to the most-common of the MCMC family) method outperforms in terms of both smaller distortion and higher efficiency of the estimates of spatial correlation and coefficients associated with explanatory variables. Development of the Bayesian MCMC gave raise to modern applications of the discrete-choice models: Holloway et al. (2002) follows Case (1992) by focusing on neighborhood effects in high-yielding variety of rice adop- 
tion in Bangladesh while updating the estimation technology by Bayesian econometrics; more recent application implement multinomial models of land use in developed countries (Chakir and Parent, 2009; Wang and Kockelman, 2014; Zhou and Kockelman, 2008).

\subsection{Spatial Autoregressive Probit}

Household $i$ 's choice to diversify, $y_{i}$, is modeled as a binary function of the latent variable associated with the utility gain from diversifying versus not diversifying, $y_{i}^{*}=U_{i \text { divesify }}-$ $U_{i-\text { divesify }}$

$$
y_{i}= \begin{cases}1 & \text { diverify with probability } p \text { if } y_{i}^{*} \geq 0 \\ 0 & \text { not diversify with probability } 1-p \text { if } y_{i}^{*}<0\end{cases}
$$

In difference to a standard binary choice framework addressed using logit or probit model, the latent variable $y_{i}^{*}$ depends not only on observable diversification determinants of household $i$ represented by $X_{i}$, but also on information flow and market conjuncture, $Y$, shaped by the other households' latent variables $y_{j}^{*}$ with $j=1 . . n, j \neq i$ and $n$ standing for the number of households:

$$
y_{i}^{*}=U_{i \text { divesify }}\left(X_{i}, Y\right)-U_{i \neg \text { diversify }}\left(X_{i}, Y\right)
$$

The spatial autoregressive probit model specifies the $n$-dimensional vector of households' latent functions, $y^{*}$, as an auto-regressive function (LeSage and Pace, 2009) which also depends on observable and unobservable factors (vectors $X$ and $\varepsilon$ respectively) that are expected to impact the diversification likelihood:

$$
y^{*}=\rho W y^{*}+X \beta+\varepsilon, \varepsilon \sim N\left(0, I_{n}\right)
$$

$W$ is a weight or contiguity matrix to be constructed. $W$ quantifies the spatial connections between households. Based on GIS coordinates, the weight matrix utilized relies 
on inverse distances ${ }^{9}$ : neighbors who are closer carry a greater weight, and this weight diminishes as the distance increases. Specifically, the weight matrix is constructed by applying the k-Nearest Neighbor Weights distance approach: a neighborhood is built ensuring that all households have at least $k=200$ neighbors ${ }^{10}$. The obtained weights are row normalized. The approach taken shares a common limitation of spatial econometrics applications consisting of imperfect reflection of underlying social and economic processes (Corrado \& Fingleton, 2012). However, LeSage and Pace (2014) show that spatial regression models are not overly sensitive to the spatial weight structure ${ }^{11}$.

$W y^{*}$ is a linear combination of neighboring latent variables related to the neighbors' decisions on diversifying.

$\rho$ is a $1 \times 1$ parameter to be estimated. It denotes the correlation between units. $\rho=0$ implies that there is no correlation and thus the model collapses to the standard probit model (Loomis and Mueller, 2013); $\rho$ different from zero $(\rho \neq 0)$ suggests that there is a correlation within the specified locations and forces endogeneity of the neighbors decisions on diversification.

$\varepsilon$ is the matrix of error terms following the standard normal distribution, $I_{n}$ is a $n \times n$ identity matrix (similarly to the standard probit approach, the variance of $\varepsilon_{i}$ is scaled to 1 for identification).

The spatial autoregressive nature of the model is similar to the time series autoregressive process: the closest neighbors are supposed to have the strongest impact on a household's decision making. A direct impact of household $i$ neighbor's activities decays with the distance between the household and its neighbors. Moreover, distant neighbors of household $i$ might have an indirect impact by enhancing information flow and projecting market influence through the closer neighbors (the effect is similar to a long term dependence in the time series framework).

The reduced form of model (2) shows that spatial dependence is inherent to both observable and unobservable factors impacting the household's decisions to diversify: 


$$
y^{*}=(I-\rho W)^{-1} X \beta+(I-\rho W)^{-1} \varepsilon
$$

It means that variation in household $i$ 's factors, $X_{i}$ or $\varepsilon_{i}$, impacts the decision of the other households with disparate intensity depending on spatial proximity captured by $W$ and strength of spatial dependence defined by $\rho$. The reduced form also shows that spatial interdependence of the outcomes induces heteroscedasticity of the error term, $(I-\rho W)^{-1} \varepsilon$.

\subsection{SAR Probit Outcomes}

As discussed above, the parameter $\rho$ represents one of the key outcomes of the analysis providing the grounds for spatial dependence. Its magnitude shows the strength of spatial dependence in outcomes related in our case to diversification decisions. Non-zero $\rho$ implies the presence of interactions among different households and synergy of local agglomeration markets. It also implies inappropriateness of the standard probit model while analyzing the impacts of variation in household characteristics on the probability to diversify.

Moreover, the estimation of $\rho$ allows simulation of propagation of unobservable exogenous shocks through space. This might capture for example diffusion of a weather shock hitting households located at point $i$ or spatial expansion of effects of a policy implemented locally.

Next, in similar fashion to the standard probit, the parameters represented by $\beta$ allow for estimation of the marginal effects of the household's observable characteristics. However, the parameter magnitudes associated with the estimated coefficients $\beta$ do not have the same marginal effects interpretation. In a spatial framework, a variation of the $k$ th explanatory variable in household $i, X_{k i}$, might have both a direct effect, that is an effect on the decision of household $i$, and an indirect effect, that is a spatial spillover effect of 
$X_{k i}$ on the decisions of the other households. Conditional on the levels of the explanatory variables, the resulting effects constitute therefore a $n \times n$ matrix $M$ rather than a $1 \times 1$ parameter as provided by the standard probit. More specifically, the matrix $M_{k}$ of the marginal effects of the $k$ th explanatory variable $X_{k}$ corresponding to the sample means of the explanatory variables, $\bar{X}$, is defined as (LeSage and Pace, 2009):

$$
M_{k}=\phi\left(\left(I_{T}-\rho W\right)^{-1} I_{T} \bar{X} \beta\right) \odot\left(I_{T}-\rho W\right)^{-1} I_{n} \beta_{X_{k}}
$$

where $\phi(\cdot)$ is the standard normal density, $I_{n}$ is a $n \times n$ identity matrix, $\odot$ represents element-by-element multiplication and $\beta_{X_{k}}$ is the coefficient associated with the specific variable $X_{k}$. Each component of the matrix contains the same base elements as a marginal effect corresponding to the standard probit: $\phi(\cdot)$ and $\beta_{X_{k}}$. However both elements are complicated by the spatial structure transmitting spillover effects.

The main diagonal elements of $M_{k}$ represent the direct impacts of a variation of $X_{k}$ on household decisions. Its average is a conventional summary measure of the direct effect, $M_{X_{k}}^{d}=n^{-1} \operatorname{tr}\left(M_{k}\right)$. Other summary measures might be the average of the row, representing the average total impact of a variation of $X_{k}$ in a given household; the average of the column, representing the average total impact of a variation of $X_{k}$ in all the households to a given household. More generally, the average total effect is the average of all the elements, $M_{X_{k}}^{t}=n^{-1} 1_{n}^{\prime} M 1_{n}$. The associated average indirect effect is the difference between the total and the direct effects, $M_{X_{k}}^{i}=M_{X_{k}}^{t}-M_{X_{k}}^{d}$.

\section{Results}

The data in use provide a number of incentives and capacity variables which allow us to test the impact of household and community characteristics on the households' propensity to diversify their income activities. Following the discussion in 2.2, we include gender, age, marital status and years of education of the household head, household composition, 
and total land owned as the model's explanatory variables relating to household-level characteristics and weather shocks and infrastructural constraints as the explanatory variables relating to the local environment.

The first column of Table 3 reports the estimates provided by the spatial auto-regressive probit model. The inference regarding the model parameters comes directly from the sets of parameters provided by the posterior distributions (LeSage and Pace, 2009). This is different from the standard frequentist approach where the confidence intervals are constructed by imaging repeated samples of data drawn under the same model. Following conventional notations of Bayesian applications, 95\% level confidence intervals are presented in brackets.

Table 3 HERE

The first result that stands out is the empirical evidence of spatial correlation: the coefficient corresponding to the intensity of the spatial dependence, $\rho$, is close to 0.5 . It is significant at the $1 \%$ level. This implies endogeneity of the neighbors' decisions to diversify their income generating activities and to allocate their productive assets among various occupations. The spatial dependence signals the importance of information flow between the households and agglomeration economics favoring the spillover of diversification activities through local markets and neighbors' networks.

Positive and significant $\rho$ implies also a double nature of the impacts relating to the observable diversification determinants: the direct marginal effects of the household's characteristics reported in the first column of Table 4 illustrate the magnitude of the corresponding impacts on the household's decision calculated at the sample means; the indirect effects reported in the second column of Table 4 illustrate the magnitude of the spillover impacts of the same determinants. The two effects sum up to the total effects reported in the third column. The $\rho$ close to 0.5 yields almost equal decomposition of the total impact in its direct and indirect parts at the sample means of the explanatory variables. 
For example, living in an urban area has a 20 percent impact on the household's likelihood to diversify its income activities; yet only 11 percent of the likelihood is a direct urban impact; the remaining 9 percent, corresponding to the indirect effect, implies that households moving to urban areas cannot expect the overall 20 percent effect as far as they do not integrate the local network and agglomeration economy.

Similarly, the model estimates suggest a double impact of the household's characteristics on its diversification decisions. The years of education of the household head affect positively and significantly the household's likelihood to diversify out of agriculture. Education may allow households to overcome barriers to entry to lucrative activities and access a broader range of income generating occupations. The corresponding direct marginal effect is 1 percent. The spillover effect implies spatial propagation of the diversification practices among more educated workers.

The household head's age is also a significant determinant of the diversification decisions. The older the head of the household is, the less likely the household diversifies out of agriculture. The direct effect is statistically significant (the magnitude is about 0.18 percent), while the indirect one is not. This implies that the age of the household's head influences the household diversification outcome without impacting the household's neighborhood. A negative age impact brings a new insight on underlying information; unlike the common association between age and capital accumulation favoring diversification, it implies that other factors and/or mechanisms may be captured: first, the head's experience in staple agriculture may have higher marginal impact on the agricultural output than on diversification gains; next, older individuals might have lower propensity to engage in multiple activities because of declining physical capabilities and increasing risk aversion to new practices and potential failing ventures.

The household structure is related to the household's likelihood to diversify income generating activities. The results are intuitive: a larger number of adults raises the probability of various activities taken on by the household members. The number of the women has a stronger direct impact (7.8 percent) than the number of men (4.4 percent) in the 
household. One of the potential reasons underlying the effect may be decreasing marginal productivity in agriculture. Nevertheless, the amount of land owned by the household is not significantly related to the household's choice to diversify. A similar result was found by Oseni and Winters (2009). The indirect positive effect of the household size is also intuitive, implying that larger families have broader networks and consequently might be subjected to stronger neighborhood influence.

The effects discussed can be compared to the estimates of the marginal effects provided by the standard probit model (column 4 of Table 4). As it can be seen, the standard probit effects are considerably lower in magnitude than the total effects obtained by using the SAR extension. The standard probit model omits the spatial interdependence component of the effects. The differences suggest that omitting the spatial component from the model might bias conclusions and mislead policy recommendations.

\section{Table 4 HERE}

The results discussed above are obtained without control for location. Columns 5-7 (Table 4) report the SAR probit outcomes from the model extended to inclusion of the state fixed effects. Controlling for the state fixed effects allows to identify the impacts of the variables which are location specific: rainfall shocks and infrastructural constraints.

Rainfall shock turns out to be the strongest determinant of the household's decision to diversify their income generating activities. This might be due to the country's reliance on rainfall as the main source of irrigation. A decrease in the percentage of rainfall experienced by the household during the post-planting season increases the likelihood of diversification. The corresponding marginal effect implies that a 10 percent shock translates to a 5 percent lower likelihood of diversifying. It is accompanied by a 1 percent spillover effect. The reliance on natural irrigation pushes farming households to diversify their income portfolios and resort to activities outside of agriculture in order to cope with downturns in farming. 
We illustrate a spatial propagation of a local rainfall shock by simulating the consequent changes of the diversification probability throughout space. A rainfall shock ${ }^{12}$ in a particular state could lead to changes in a region's likelihood of diversification. Specifically, a 20 percent negative rainfall shock is simulated in the state of Kogi in the central region of Nigeria. Figure 11 shows that the shock yields an increase of the diversification likelihood not only in Kogi but also in the surrounding states, while the states which are farther away are not affected.

Improved infrastructure access pulls households to diversify by easing access to opportunities. However, while considered as a strong diversification factor in the literature, infrastructural constraints play a small role in the diversification outcomes among the Nigerian farming households. This result suggests that the income diversification process in Nigeria is possibly held back by push factors: a response to need might be of higher importance than broader lucrative opportunities; yet, more detailed community data are needed to further the research in this direction.

The standard probit results relating to the extended model are closer to the SAR version output since controlling for the state fixed effects captures a great deal of the correlations between the neighbors' outcomes. Indeed, the observations relating to the households from the same state represent neighboring outcomes. Nevertheless, the spatial interdependence parameter is positive and significant in this case while its magnitude is less important: the estimated $\rho$ is about 0.2 . Weaker $\rho$ implies weaker indirect marginal effects respectively.

\subsection{Regional Outcomes}

This subsection extends the study by analyzing separately the northern and southern parts of Nigeria. As sections 3 and 4 point out, the two parts of the country represent very different geographical and economic zones so that the outcomes might differ significantly between them and the overall results might be driven by the specific outcomes of one 
zone. The northern results are presented in Tables 5 and 6 , the southern results are reported in Tables 7 and 8 .

\section{Tables 5-6 HERE}

The main difference between the regional results relates to the strength of spatial dependence. Based on the northern sub-sample, the base SAR probit model (the SAR model that does not include the state fixed effects) yields the same estimate as the estimate reported at the national level, $\rho=0.5$. The southern estimate is significantly lower yielding $\rho=0.4$. As before, the extended model shows lower levels of spatial interdependence of the outcomes due to the state fixed effects partly capturing it. The corresponding estimates point out further to the northern sub-sample prevalence in the spatial correlations of the outcomes. They imply $\rho=0.3$ for the northern households, which is stronger than the estimate yielded by the extended model based on the whole sample, and $\rho$ not significantly different from zero for the southern households ${ }^{13}$.

The regional gap is partly mechanical. Indeed, the southern states are of the smaller size and of higher population density. Technically this implies a larger number of close neighbors among southern households and strong correlation of their outcomes captured by the fixed state effects. However, the gap shown by the model that does not control for the state effects provides evidence of an effectively lower spatial interdependence in the South as compared to that in the North. An insignificant $\rho$ implies validity of the standard probit model for analyzing the diversification decisions of the southern households.

\section{Tables 7-8 HERE}

Despite the higher concentration of cities and industries in the South of the country and lower level of development and urbanization in the North (section 3), the southern results show higher importance of the infrastructural constraints in regards to the household's likelihood to diversify its income activities. While both, SAR and standard probit models yield similar estimates of the direct impact of infrastructure access impact in the North, 
the SAR estimate is more efficient; reliance on the standard probit model would lead to an erroneous conclusion of insignificance of the variable. The regional difference might be a signal of a different nature of the factors underlying the diversification decisions of the southern and northern households: more favorable for diversification infrastructural environment might represent a pull factor for the southern households, while northern ones might be less sensitive to the pull factors and rely more on the push ones.

Different degrees of development and urbanization might also explain the gender differences in the regional outcomes on diversification decisions. In the South, the marginal impact of more men in the household is higher than the marginal impact of more women (5.8 percent versus 3.9 percent according to the standard probit estimates). In the North, it is a higher number of the female members of the households that is beneficial to diversification (6 percent correspond to the direct marginal effect and 2.5 percent account for the spillover marginal effect). This may be related to the limited role that Nigerian women play in northern agriculture and higher poverty of the northern region pushing them to look for additional income activities.

A final difference between regions which emerges is the significance of education of the household head. The result reported at the national level is driven by the northern sample: an additional year of education in the North is related to a 1.2 percent increase of the household's likelihood to diversify; in the South of the country education is not a significant determinant of diversification. This might be explained by stronger barriers to income generating activities out of agriculture in the North and consequent role of education to facilitate the access. Nevertheless, it is possible that this variable suffers from endogeneity.

\subsection{Sectoral outcomes}

Refining the analysis by focusing on sectoral diversification (non-farm or farm diversification) or associating diversification with a specific activity such as non-farm entrepreneurship (most frequent among Nigerian households) or planting cash crop (also 
highly present), reveals that the diversification results discussed above are driven by non-farm diversification at both national and regional levels (Tables 9-11). This is not surprising given that non-farm entrepreneurship is the main diversifying activity among Nigerian farming households.

\section{Tables 9-11 HERE}

Farm diversification shows very different results: among the significant ones are very high spatial correlation (fixed effects being controlled for) and a slight positive association between agricultural commercialization and hectares owned. Strong spatial association is likely to capture not only spillover effects relating to social learning and networking among the cash cropping households ('contagion' effect) but also spatial association of agroconditions other than rainfall shocks ('common exposure' effect): varying topography and soil quality favor regional agricultural specialization (Aregheore, 2009) shown by Figure 2 .

Positive association between acreage and cash cropping is a common finding in the literature on agricultural commercialization: small landholding and associated poverty might be a strong barrier to cash cropping because of insufficient land and inputs endowments; food insecurity related to market imperfections also discourages smaller landholders from agricultural commercialization. The effect is however very weak in the Nigerian case with land elasticity of the cash cropping likelihood being at highest 0.08 in the South with 0.05 direct and 0.03 indirect effects respectively (Table B.2, Appendix B).

Finally, a rainfall shock does not impact the likelihood of cash cropping while it is a push factor to diversify outside of the family's own farm including farm wage activity. Thus, development of irrigation system may not have an impact on cash cropping likelihood and would decrease households' incentives to diversify off-farm. 


\section{Conclusions}

This study presents new evidence of the important role of spatial interdependence of household decisions in developing economies to diversify their income generating activities. The evidence is obtained taking advantage of the Nigerian household survey providing GIS coordinates for the surveyed households and incorporating spatial dependence in the choice model of income diversification. The model is estimated using advanced econometric techniques consisting of the spatial auto-regressive probit model and a Bayesian estimation strategy.

The resulting estimate of spatial correlation implies endogeneity of neighbors' decisions to allocate their productive assets among various occupations and signals the importance of social learning and agglomeration effects favoring the spillover of diversification activities through neighbor networks and local markets. The result suggests multiple impacts of the observable diversification determinants: the paper reports a direct effect of the household's characteristics associated with various diversification factors on the household's diversification choice and a spillover effect of the same variables on the decisions of the other households.

The households' decisions respond also to the local environment. Weather shock is a strong pushing factor of the diversification out of agriculture activities to cope with downturns in farming. A pulling factor found is improved infrastructure access. However, the weakness of the effect suggests that the income diversification process in Nigeria is possibly held back by push factors: a response to need might prevail over broader entrepreneurship. More detailed community data are needed to further the research in this direction. Additionally, possible development of the future agenda is employing new information resources on weather conditions, road network, nightlight density, etc. coming from satellite data recorded by the air forces and provided by geophysical agencies.

Given regional differences in development and urbanization, region-specific effects in regards to infrastructural constraints might signal different nature of the factors underlying 
the diversification decisions of households living in different areas: a more favorable infrastructural environment for diversification might represent a pull factor for households settled in more developed zones, while farmers living in less developed regions might be less sensitive to the pull factors and rely more on the push ones. Further research should be done on framing structural elements corresponding to the diversification factors of different nature as well as shaping specific channels of the spillover effects.

The evidence of the spillover effects is instructive in terms of a policy perspective by implying that a local environmental shock or a program implemented locally might have impacts propagated beyond a given locality and a targeted population. A relatively weak local effect of infrastructural development on diversification among the farming households in less developed regions such as Northern Nigeria might be compensated by stronger diffusive effects among the households engaging into non-farm entrepreneurship. Furthermore, investments in NFE capacity empowerment, such as education, are likely to have stronger propagation effects on NFE development through knowledge and information transfers among northern households showing higher social dependence of their diversification practices. Cash cropping incentives and land endowment policies are likely to have particularly strong ripple effects on agricultural commercialization in both regions; yet future research should refine the analysis to disentangle 'common exposure' and 'contagion' spatial effects among cash cropping households.

The approach might also be methodologically insightful for experimentalists building policy evaluations on the randomized controlled trials (RCT). Indeed, a large body of literature raises concerns about internal validity of randomized evaluations in developing economies (see Teele (2014) who settled a large debate assembling views of the experiments advocates and critics). One of the concerns is the difficulty of double blindness in the framework of RCT and the important role of the perceived difference in outcomes between agents assigned and not assigned to a policy providing a resource or technology. Taking into account interdependence of households' decisions in developing economies might reduce a potential bias induced by non-blinded randomization compromising the internal validity of RCT results. 
A limitation of the work is the use of a cross-section. Allowing for spatio-temporal variation based on use of a panel warrants an avenue for future research to build on longer panels and further advances in spatial econometrics in terms of panel discrete choice modeling and endogeneity of the contiguity matrix; the latter would allow to capture endogenous changes of the sample which might relate to households' leave location and/or dropping from farming. Another promising development is differentiating individual decisions of household members and integrating intra-household diversification decision-making into the analysis. 


\section{Notes}

${ }^{1}$ We gratefully acknowledge cooperation of the LSMS team at the World Bank providing us with GIS data access at the household level of the first wave of the survey.

2The term 'non-farm' is considered across the literature separately from 'off-farm' (Gordon and Craig, 2001). Off-farm refers to any activity which is performed outside of the family's own farm, including farm labor on neighboring farms.

${ }^{3}$ This is in line with two findings common not only for developed countries but also for developing economies. The first one is intergenerational transmission of human capital (Breierova and Duflo, 2004, for instance) showing positive correlation between parent's and children's attainments. The second finding is spouses' positive assortative matching on education which translates into positive correlation between spouses' level of education.(See for example Torche (2010) for Latin America examples and Assaad and Krafft (2015) for African ones).

${ }^{4}$ Glaeser (2010, p.1) defines these as "the benefits that come when firms and people locate near one another together in cities and industrial clusters."

${ }^{5}$ Households for which land measures were not available were removed.

${ }^{6} \mathrm{t}=2009$ for wave 1.

${ }^{7}$ These are all aggregated into one index due to their high correlation. At the aggregation, variables have positive loading factors of roughly the same order.

${ }^{8}$ See Fleming (2004) and a more recent work of Calabrese and Elkink (2014) for comprehensive reviews.

${ }^{9}$ The distances are estimated by great circle.

${ }^{10}$ The k-Nearest Neighbor Weights is a distance-based approach very close to just inverse weight matrix: the difference consists in attributing a zero weight to too distant neighbors. This implies that for the weight of neighbors remote by more than $372 \mathrm{~km}$ (which is the maximum distance between a household and its most distant "neighbor" under k equaling 200) is approximated by 0 . This is not a rough approximation since the inverse of 372 is very close to zero (0.003). On the other hand, the zero approximation of the weight of too distant neighbors allows to considerably alleviate the calculus without any considerable loss of spatial information by using a sparse matrix, that is a matrix containing a large 
proportion of zeros. A sparse matrix can be stored considerably more efficiently at the calculation process: in our case of 2727 observations and k equaling 200, it contains $200 \times 2527$ non zero elements instead of $2727 \times 2727$ for a dense inverse matrix taking into account additional 2527 very distant neighbors whose weights are close to zero.

${ }^{11}$ We check the robustness of the results using inverse distance weight matrix with at least 10 neighbors and with full sample neighbors. The estimates are very close to the original ones based on 200 neighbors (Table B.1, Appendix B): the very light differences in the coefficient estimates are totally smoothed out at the marginal effects. We explain this by the very weak weights carried out by the neighbors living farther than a few km away.

${ }^{12}$ All else being equal

${ }^{13}$ To test that the regional separation does not act as a barrier to spatial spillovers, we also estimate the extended model using a subsample of the households living within the South-North border delimited by the 6th and 9.1th parallel south (6 and 9.1 latitudes correspond to the southernmost point of the Nigerian North and the northernmost point of the Nigerian South). The corresponding spatial dependence coefficient is not statistically significant supporting the regional divide of the sample. 


\section{References}

Abdulai, A. \& Crole-Rees, A. (2001). Determinants of income diversification amongst rural households in southern mali. Food Policy, 26, 437-452.

Abdulai, A. \& CroleRees, A. (2001). Determinants of income diversification amongst rural households in southern mali. Food Policy, 26, 437-452.

Abdulai, A. \& Delgado, C. (1999). Determinants of nonfarm earnings of farm-based husbands and wives in northern ghana. American Journal of Agricultural Economics, 81(1), 117-130.

Albert, J. H. \& Chib, S. (1993). Bayesian analysis of binary and polychotomous response data. Journal of the American statistical Association, 88(422), 669-679.

Anselin, L. (1995). Local indicators of spatial association - lisa. Geographic Analysis, $27(2), 93-115$.

Aregheore, E. M. (2009). Country pasture/forage resource profiles. Food and Agriculture Organization of the United Nations (FAO).

Assaad, R. \& Krafft, C. (2015). The economics of marriage in north africa: A unifying theoretical framework. In The Oxford Handbook of Africa and Economics: Policies and Practices, Celestin Monga and Justin Yifu Lin (Eds.).Oxford: Oxford University Press, (pp. 72-85).

Babatunde, R. (2013). On-farm and off-farm works: Complement or substitute? evidence from rural nigeria.

Babatunde, R. \& Qaim, R. (2009). Patterns of income diversification in rural nigeria: Determinants and impacts. Quarterly Journal of International Agriculture, 48(4), 305320.

Babatunde, R. O. (2012). Assessing the effect of off-farm income diversification on agricultural production in rural nigeria. 
Babatunde, R. O. \& Qaim, M. (2010). Impact of off-farm income on food security and nutrition in nigeria. Food policy, 35(4), 303-311.

Barrett, C. B., Bezuneh, M., \& Aboud, A. (2001a). Income diversification, poverty traps and policy shocks in cote d'ivoire and kenya. Food Policy, 26(4), 367-384.

Barrett, C. B., Clark, M. B., Clay, D. C., \& Reardon, T. (2005). Heterogeneous constraints, incentives and income diversification strategies in rural africa. Quarterly journal of international agriculture, 44(1), 37-60.

Barrett, C. B., Reardon, T., \& Webb, P. (2001b). Nonfarm income diversification and household livelihood strategies in rural africa: concepts, dynamics, and policy implications. Food policy, 26(4), 315-331.

Beron, K. J. \& Vijverberg, W. P. (2004). Probit in a spatial context: a monte carlo analysis. In Advances in spatial econometrics. Methodology, tools and applications, ed. Luc Anselin, Raymond J.G.M. Florax and Sergio J. Rey. Berlin: Springer, (pp. 169-195.).

Bloch, R., Monroy, J., Fox, S., \& Ojo, A. (2015). Urbanization and urban expansion in nigeria. Urbanisation Research Nigeria (URN) Research Report. London: ICF International.

Brady, M. \& Irwin, E. (2011). Accounting for spatial effects in economic models of land use: Recent developments and challenges ahead. Environmental and Resource Economics, 48(3), 487-509.

Breierova, L. \& Duflo, E. (2004). The impact of education on fertility and child mortality: Do fathers really matter less than mothers? NBER Working Papers 10513.

Breustedt, G. \& Habermann, H. (2011). The incidence of eu per-hectare payments on farmland rental rates: A spatial econometric analysis of german farm-level data. Journal of Agricultural Economics, 62(1), 225-243. 
Calabrese, R. \& Elkink, J. A. (2014). Estimators of binary spatial autoregressive models: A monte carlo study. Journal of Regional Science, 54(4), 664-687.

Cameron, A. C. \& Trivedi, P. K. (2005). Microeconometrics: methods and applications. Cambridge university press.

Canagarajah, S., Newman, C., \& Bhattamishra, R. (2001). Non-farm income, gender, and inequality: Evidence from rural ghana and uganda. Food Policy, 26(4), 405-420.

Case, A. (1992). Neighborhood influence and technological change. Regional Science and Urban Economics, 22(3), 491-508.

Chakir, R. \& Parent, O. (2009). Determinants of land use changes: A spatial multinomial probit approach. Papers in regional science, 88(2), 327-344.

Corrado, L. \& Fingleton, B. (2012). Where is the economics in spatial eonometrics? Journal of Regional Science, 52(2), 210-239.

Corral, L. \& Reardon, T. (2001). Rural non-farm incomes in nicaragua. World Development, 29(3), 427-442

Corral, P., Molini, V., \& Oseni, G. (2015). No condition is permanent: middle class in nigeria in the last decade. World Bank Policy Research Working Paper, (7214).

Davis, B., Winters, P., Reardon, T., \& Stamoulis, K. (2009). Rural nonfarm employment and farming: household-level linkages. Agricultural Economics, 40(2), 119-123.

De Janvry, A., Sadoulet, E., \& Zhu, N. (2005). The role of non-farm incomes in reducing rural poverty and inequality in china. Department of Agricultural \& Resource Economics, $U C B$.

De Pinto, A. \& Nelson, G. C. (2007). Modelling deforestation and land-use change: Sparse data environments. Journal of Agricultural Economics, 58(3), 502-516.

Djurfeldt, A. (2012). African re-agrarianization? accumulation or pro-poor agricultural growth? World Development, 41, 217-231. 
Ekpoh, I. J. \& Nsa, E. (2011). Extreme climatic variability in north-western nigeria: an analysis of rainfall trends and patterns. Journal of Geography and Geology, 3(1), 51.

Escobal, J. (2001). The determinants of nonfarm income diversification in rural peru. World Development, 29(3), 497-508.

Fafchamps, M. \& Minten, B. (1998). Returns to social capital among traders. International Food Policy Research Institute (IFPRI) Discussion Paper, (23).

Filmer, D. \& Pritchett, L. H. (2001). Estimating wealth effects without expenditure dataor tears: An application to educational enrollments in states of India*. Demography, 38(1), 115-132.

Fleming, M. M. (2004). Techniques for estimating spatially dependent discrete choice models. In Advances in spatial econometrics. Methodology, tools and applications, ed. Luc Anselin, Raymond J.G.M. Florax and Sergio J. Rey. Berlin: Springer, (pp. 145$167)$.

Franzese, R. \& Hays, J. (2014). Testing for spatial-autoregressive lag versus (unobserved) spatially correlated error-components. Benjamin F. Shambaugh conference: New frontiers in the study of policy diffusion, University of Iowa, Iowa City.

Franzese, R. J., Hays, J. C., \& Schaffer, L. M. (2010). Spatial, temporal, and spatiotemporal autoregressive probit models of binary outcomes: estimation, interpretation, and presentation. In APSA 2010 annual meeting paper.

Glaeser, E. L. (2010). Agglomeration economics. University of Chicago Press.

Goldstein, M., Mchich, K., Montalvao, J., Munoz, M., O’Sullivan, M., \& Zikronah, B. (2013). "you can't eat cotton": Evidence on crop portfolios and gender from benin. Working paper.

Gordon, A. \& Craig, C. (2001). Rural non-farm activities and poverty alleviation in sub-Saharan Africa. Natural Resources Institute, University of Greenwich. 
Haggblade, S. (2007). Alternative perceptions of the rural non farm economy. Transforming the Rural Nonfarm Economy: opportunities and threats in the developing world, (pp. 262-319).

Holloway, G., Lacombe, D., \& LeSage, J. P. (2007). Spatial econometric issues for bioeconomic and land-use modelling. Journal of Agricultural Economics, 58(3), 549-588.

Holloway, G. \& Lapar, M. L. (2007). How big is your neighbourhood? spatial implications of market participation among filipino smallholders. Journal of Agricultural Economics, $58(1), 37-60$.

Holloway, G., Shankar, B., \& Rahmanb, S. (2002). Bayesian spatial probit estimation: a primer and an application to hyv rice adoption. Agricultural Economics, 27(3), 383402.

Klier, T. \& McMillen, D. P. (2008). Clustering of auto supplier plants in the united states: generalized method of moments spatial logit for large samples. Journal of Business and Economic Statistics, 26(4), 460-471.

Lanjouw, P. (2001). Nonfarm employment and poverty in rural el salvador. World Development, 29(3), 529-547.

LeSage, J. \& Pa (2014). The biggest myth in spatial econometrics. Econometrics, 2, $217-249$.

LeSage, J. \& Pace, R. K. (2009). Introduction to spatial econometrics. CRC press.

Liu, Z. \& Lan, J. (2015). The sloping land conversion program in china: Effect on the livelihood diversification of rural households. World Development, 70, 147-161.

Loomis, J. B. \& Mueller, J. M. (2013). A spatial probit modeling approach to account for spatial spillover effects in dicotomous choice contingent valuation surveys. Journal of Agricultural and Applied Economics, 45(01).

McMillen, D. P. (1992). Probit with spatial autocorrelation. Journal of Regional Science, $32(3), 335-348$. 
Miguel, E., Satyanath, S., \& Sergenti, E. (2004). Economic shocks and civil conflict: An instrumental variables approach. Journal of political Economy, 112(4), 725-753.

Nelson, G. C. (2002). Introduction to the special issue on spatial analysis for agricultural economists. Agricultural Economics, 27, 197-200.

Oseni, G., Corral, P., Goldstein, M., \& Winters, P. (2015). Explaining gender differentials in agricultural production in nigeria. Agricultural Economics, 46(3), 285-310.

Oseni, G. \& Winters, P. (2009). Rural nonfarm activities and agricultural crop production in nigeria. Agricultural Economics, 40(2), 189-201.

Pinkse, J. \& Slade, M. E. (1998). Contracting in space: an application of spatial statistics to discrete-choice models. Journal of Econometrics, 85, 125-154.

Reardon, T., Berdegue, J., Barrett, C. B., \& Stamoulis, K. (2007). Household Income Diversification into Rural Nonfarm Activities. Baltimore: Johns Hopkins University Press.

Schmidtner, E., Lippert, C., Engler, B., Haring, A. M., Aurbacher, J., \& Dabbert, S. (2012). Spatial distribution of organic farming in germany: does neighbourhood matter? European Review of Agricultural Economics, 39(4), 661-683.

Senadza, B. (2012). Non-farm income diversification in rural ghana: Patterns and determinants. African Development Review, 24(3), 233-244.

Smith, T. E. \& LeSage, J. P. (2004). A bayesian probit model with spatial dependencies. Advances in econometrics, 18, 127-160.

Tanner, M. A. \& Wong, W. H. (1987). The calculation of posterior distributions by data augmentation. Journal of the American statistical Association, 82(398), 528-540.

Teele, D. L. (2014). Field experiments and their critics: essays on the uses and abuses of experimentation in the social sciences. Yale University Press. 
Torche, F. (2010). Educational assortative mating and economic inequality: A comparative analysis of three latin american countries. Demography, 47(2), 481-502.

Wang, Y. \& K.M., K. (2014). A spatial autoregressive multinomial probit model for anticipating land use change in austin. Annals of Re, 52, 251-278.

Weldegebriel, Z. B., Folloni, G., \& Prowse, M. (2015). The determinants of non-farm income diversification in rural ethiopia. Journal of Poverty Alleviation and International Development, 6(1), 109-130.

Wilhelm, S. \& de Matos, M. G. (2013). Estimating spatial probit models in r. R Journal, 5(1), 130-43.

Winters, P., Davis, B., Carletto, G., Covarrubias, K., Quinones, E. J., Zezza, A., Azzarri, C., \& Stamoulis, K. (2009). Assets, activities and rural income generation: Evidence from a multicountry analysis. World Development, 37(9), 1435-1452.

Woldenhanna, T. \& Oskam, A. (2001). Income diversification and entry barriers: Evidence from the tigray region of northern ethiopia. Food Policy, 26(4), 351-365.

Zellner, A. (1971). An introduction to Bayesian inference in econometrics. New York: J. Wiley.

Zhou, B. \& Kockelman, K. M. (2008). Neighborhood impacts on land use change: a multinomial logit model of spatial relationships. Annals of Regional Science, 42(2), $321-340$. 


\section{Appendix A. Estimation}

\section{Bayesian Model}

The standard probit model is easily estimated by the maximum likelihood estimator (MLE). Cross sectional data imply independence of observations and consequent separability of the likelihood function: independence of households' decisions means that the joint distribution of the corresponding outcomes can be represented as a product of individual distributions. The resulting log-likelihood function is formed then as a sum of $\log$ forms of univariate cumulative densities implying a one-dimensional integration.

The panel variant of the probit-type models entails multidimensional integration due to non-separability of the distribution of the outcomes related to the same entity (for instance the same household observed several times). The level of multiple dimensionality in this case corresponds to the number of cross sections within the panel. While multidimensionality here complicates the statistical model, it is still tractable by the MLE analytically or using its simulated version.

Similarly, a maximum likelihood function can be formed in the framework of the spatial probit. However the level of the dimensionality in this case corresponds to the number of entities and implies a $n$-dimensional non-separable distribution. Maximization of the corresponding likelihood function is very computationally intensive (LeSage and Pace, 2009) even with today's powerful computers. An alternative suggested in the spatial econometrics literature is Bayesian methods which do not require maximization algorithms (Cameron and Trivedi, 2005). We follow therefore a Bayesian strategy suggested by LeSage and Pace (2009) and implemented by Wilhelm and de Matos (2013).

In general, a Bayesian approach consists of introducing a density $\pi(\beta, \rho)$ for the prior distribution of the parameters of interest (vector $\beta$ relates to the explanatory variables and scalar $\rho$ relates to the intensity of spatial dependence) and updating the prior beliefs about the parameters by the sample data, that is by the likelihood function available from 
the data ${ }^{14}$. The resulting posterior distributions of the parameters of interest allow the researcher to make statements about the probabilities of specific values and report the model outcomes of interest outlined above. Uncertainty about $\beta$ and $\rho$ is thus modeled explicitly. This is different from non-Bayesian approaches assuming a unique true value of a parameter and having to imagine repeated samples of data drawn under the same model to produce statistical inference (classical t-statistics and 95\% confidence intervals).

The priors assigned to $\beta$ and $\rho$ are assumed independent. This independence reflects prior beliefs that can be inconsistent with posterior outcomes but does not imply independence in the posterior distributions of the parameters. We follow then LeSage and Pace (2009) by using a conventional normal prior for $\beta$ :

$$
\pi(\beta) \propto N(c, T)
$$

and a non-informative prior for $\rho$. The non-informative prior has minimal impact on the posterior distributions and is used in the event of little experience and knowledge about a parameter. In our case it is a flat (uniform) distribution implying equal probability of all the values of $\rho$, it is therefore proportional to a constant:

$$
\pi(\rho) \propto \text { constant }
$$

Following conventional notations, let $D$ represent the model data, that is the set $\{y, X, W\}$. From the Bayes' theorem, the product of the likelihood related to the sample data, $p(D \mid \beta, \rho)$, and the priors determine the form of the posterior up to a constant:

$$
p(\beta, \rho \mid D) \propto p(D \mid \beta, \rho) \pi(\beta) \pi(\rho)
$$

The joint posterior $p(\beta, \rho \mid D)$ would be difficult to analyze. First, in order to obtain the mean and variance of $\beta$ and $\rho$, the marginal distributions of $\beta$ and $\rho$ are required. 
A marginal posterior distribution of a given parameter might have a complex shape, it is not necessarily unimodal and requires integrating out of all the other joint posterior parameters (recall that $\beta$ is a vector) entailing multidimensional integration of $p(\beta, \rho \mid D)$.

Moreover, the binary nature of the data outcome $y$ makes the problem intractable and requires a special consideration consisting of the data augmentation (LeSage and Pace, 2009): the observed data $D=\{y, X, W\}$ is augmented by the latent variable $y^{*}$ (so that $\left.D=\left\{y, y^{*}, X, W\right\}\right)$ to reduce the complexity of the joint posterior $p(\beta, \rho \mid y)$ and focus instead on $p\left(\beta, \rho \mid y, y^{*}\right)^{15}$. The insight of the data augmentation is given by Tanner and Wong (1987) and Albert and Chib (1993): if the latent $y^{*}$ were known, the posterior $p\left(\beta, \rho \mid y, y^{*}\right)$ would be easier to analyze. In our framework indeed, knowledge of $y^{*}$ would turn the reduced SAR probit (3) to the spatial autogregressive model with a continuous outcome which has well established tractable joint and conditional posteriors. The interconnection between $y$ and $y^{*}$ implies that knowledge of $y^{*}$ would yield knowledge of $y$ so that $p\left(\beta, \rho \mid y, y^{*}\right)=p\left(\beta, \rho \mid y^{*}\right) . y^{*}$ is unobserved, but can be viewed as an additional set of parameters to be estimated in the framework of the SAR probit. Its conditional distribution is easily predicted from (3). Then the joint posterior can be summarized as

$$
p\left(\beta, \rho \mid y^{*}\right) \propto p\left(y^{*} \mid \beta, \rho\right) \pi(\beta) \pi(\rho)
$$

The difficulty of calculating the marginal posterior distributions of interest (those of $\beta$ and $\rho$ ) motivates use of Markov Chain Monte Carlo methods (MCMC) as an alternative approach offered in the recent literature for the estimation of Bayesian spatial models (LeSage and Pace, 2009). The method is detailed below. 


\section{MCMC Estimation}

A simulation technique is an alternative to the analytic approach which is offered in the recent literature (LeSage and Pace, 2009) as a solution for the estimation of Bayesian spatial models. It consists of simulation of a large sample from the posterior distribution allowing the researcher to study the distribution and its key moments without calculating explicitly its density. The complexity of the joint posterior distribution does not allow simultaneous draws of the parameters $\beta, \rho$ and $y^{*}$ and motivates their sequential draws. The simulated values drawn sequentially converge to a stationary distribution identical to the target posterior density. The resulting Markov Chain is constructed using the Gibbs sampler.

The Gibbs sampler requires knowledge of the conditional posteriors, that is $p\left(\beta \mid \rho, y^{*}\right)$, $p\left(\rho \mid \beta, y^{*}\right)$ and $p\left(y^{*} \mid \beta, \rho\right)$. Starting with some initial values $\beta^{(0)}, \rho^{(0)}, y^{*(0)}$, the algorithm consists in cycling through the parameters and simulating directly from the conditional posterior distributions:

1) Sampling $y^{*(t+1)}$ from $p\left(y^{*} \mid \beta^{(t)}, \rho^{(t)}\right)$

2) Sampling $\beta^{(t+1)}$ from $p\left(\beta \mid \rho^{(t)}, y^{*(t+1)}\right)$

3) Sampling $\rho^{(t+1)}$ from $p\left(\rho \mid \beta^{(t+1)}, y^{*(t+1)}\right)$

where superscript $(t)$ denotes the $t$-th cycling pass. The resulting stochastic sequence of the parameters is a Markov Chain: the parameter values randomly drawn at each $(t+1)$ th cycle depend on their immediate predecessors from the $t$-th cycling pass. It represents the marginal posterior distributions of interest: $p(\beta)$ and $p(\rho)$. The statistics of interest for the key parameters represent the population parameters of interest (Franzese et al. 2010). They can be obtained from the sets of the simulated values.

The conditional distribution of the unobserved latent function, $p\left(y^{*} \mid \beta, \rho\right)$, is directly defined by the reduced SAR probit described by (1) and (3). Given the standard normal distribution of $\varepsilon$, the latent variable defined by $y^{*}=A^{-1} X \beta+A^{-1} \varepsilon$ with $A$ standing 
for the matrix $\left(I_{n}-\rho W\right)$ is distributed following a truncated multi-normal distribution. The corresponding density is defined from (3):

$$
p\left(y^{*} \mid \beta, \rho\right)=(2 \pi)^{-\frac{n}{2}}|A| \exp \left(-\frac{1}{2}\left(A y^{*}-X \beta\right)^{\prime}\left(A y^{*}-X \beta\right)\right)
$$

subject to $y^{*} \geq 0$ if $y=1$ and $y^{*}<0$ if $y=0$. The determinant of $A$ arises from the Jacobean of the transformation between $y^{*}$ and $\varepsilon$ : given that $\varepsilon=A y^{*}-X \beta, p\left(y^{*}\right.$ $\beta, \rho)=p(\epsilon \mid \beta, \rho) \cdot\left|\frac{d \varepsilon}{d y^{*}}\right|=p(\epsilon \mid \beta, \rho) \cdot|A|$.

The form of the conditional posterior for $\beta$ can be derived by pooling its prior (4) and the likelihood defined by (6). Both densities being multivariate normal, the resulting conditional posterior is also multivariate normal:

$$
\begin{aligned}
p\left(\beta \mid \rho, y^{*}\right) & \propto p\left(y^{*} \mid \beta, \rho\right) \pi(\beta) \\
& \propto N\left(c^{*}, T^{*}\right)
\end{aligned}
$$

The parameters $c^{*}, T^{*}$ of the distribution are given by LeSage and Pace (2009) and are based on classical results of Bayesian econometrics (see for exampleZellner, 1971):

$$
\begin{gathered}
c^{*}=\left(X^{\prime} X+T^{-1}\right)^{-1}\left(X^{\prime} A y^{*}+T^{-1} c\right) \\
T^{*}=\left(X^{\prime} X+T^{-1}\right)^{-1}
\end{gathered}
$$

The results (7)-(8) can also be seen as related to the distribution of the "mixed estimator" of the "augmented regression model" (Cameron and Trivedi, 2005) pooling the Bayesian prior (4) and the likelihood associated with the reduced model $A y^{*}=X \beta+\varepsilon$ :

$$
\left[\begin{array}{c}
A y^{*} \\
c
\end{array}\right]=\left[\begin{array}{c}
X \\
I
\end{array}\right] \beta+\left[\begin{array}{l}
\varepsilon \\
v
\end{array}\right]
$$

where $v$ is the error term related to the deviation of the prior $\beta$ from its mean $c$ and follow- 
ing a normal distribution with zero mean and variance-covariance matrix $T, v \sim N(0, T)$. $c^{*}$ and $T^{*}$ as defined by (7)-(8) are then the parameters of the normal distribution followed by a GLS estimator of system (9).

The form of the conditional posterior for $\rho$ is derived pooling the likelihood (6) and the prior (5):

$$
\begin{aligned}
p\left(\rho \mid \beta, y^{*}\right) & \propto p\left(y^{*} \mid \beta, \rho\right) \pi(\rho) \\
& \propto|A| \exp \left(-\frac{1}{2}\left(A y^{*}-X \beta\right)^{\prime}\left(A y^{*}-X \beta\right)\right)
\end{aligned}
$$

where the constant term $(2 \pi)^{-\frac{n}{2}}$ is omitted along with a constant corresponding to the flat prior $\pi(\rho)$ (the posterior is only required to be defined up to a multiplicative constant: since two proportional likelihood functions contain the same information about the parameters, the additives and multipliers invariant with respect to the parameters whose distribution is under the focus are to be ignored). Further simplification though is not possible implying that the conditional density for $\rho$ is non trivial.

The draw from a multivariate normal distribution is straightforward; the draws from non-standard distributions as those of conditional $y^{*}$ and $\rho$ require special simulation techniques. The results reported below are obtained relying on Wilhelm and de Matos (2013) who use a Gibbs sampler for $y^{*}$ and "drawing by inversion" approach of Smith and LeSage (2004) for $\rho^{16}$. The latter requires a grid-based evaluation of a cumulative density function for $p\left(\rho \mid \beta, y^{*}\right)$ carried out by univariate numerical integration (LeSage and Pace, 2009, p.132 and 138-139).

\section{Notes}

\footnotetext{
${ }^{14}$ We follow conventional notations of the Bayesian literature using $\pi$ for denoting a prior distribution and $\propto$ for proportionality symbol.
} 
${ }^{15} X, W$ are conventionally omitted from the condition for simplicity of the presentation.

${ }^{16} \mathrm{An}$ alternative technique used more frequently in the applied literature is the Metropolis Hastings algorithm (Franzese et al. 2010) but it is less efficient and more time-consuming because of an important rejection rate of draws (LeSage and Pace, 2009). 


\title{
Appendix B. Robustness check
}

\author{
Table B.1 HERE
}

\begin{tabular}{|c|c|c|c|}
\hline & $S A R$ (1) & $S A R$ (2) & $S A R$ (3) \\
\hline Variables & Diversified & Diversified & Diversified \\
\hline \multirow[t]{2}{*}{ Nat. log of hectares owned } & 0.0043 & 0.0037 & 0.0076 \\
\hline & $(0.0221)$ & $(0.0221)$ & $(0.0222)$ \\
\hline \multirow[t]{2}{*}{ Wealth index } & & & $0.2126^{* * *}$ \\
\hline & & & $(0.0325)$ \\
\hline \multirow[t]{2}{*}{ Female headed } & 0.1092 & 0.1057 & 0.0832 \\
\hline & $(0.1463)$ & $(0.1452)$ & $(0.1451)$ \\
\hline \multirow[t]{2}{*}{ Head's age } & $-0.0082 * * *$ & $-0.0083^{* * *}$ & $-0.0085^{* * *}$ \\
\hline & $(0.002)$ & $(0.0021)$ & $(0.0021)$ \\
\hline \multirow[t]{2}{*}{ Head is married } & $0.3861^{* * *}$ & $0.379^{* * *}$ & $0.372^{* * *}$ \\
\hline & $(0.1248)$ & $(0.1251)$ & $(0.1237)$ \\
\hline \multirow[t]{2}{*}{ Head's educ. years } & $0.0236^{* * *}$ & $0.0241^{* * *}$ & $0.0109 *$ \\
\hline & $(0.0061)$ & $(0.0061)$ & $(0.0347)$ \\
\hline \multirow[t]{2}{*}{ Adult females } & $0.1397^{* * *}$ & $0.1408 * * *$ & $0.1225 * * *$ \\
\hline & $(0.0322)$ & $(0.033)$ & $(0.0325)$ \\
\hline \multirow[t]{2}{*}{ Adult males } & $0.1106^{* * *}$ & $0.1113^{* * *}$ & $0.0887 * * *$ \\
\hline & $(0.0332)$ & $(0.0331)$ & $(0.0341)$ \\
\hline \multirow[t]{2}{*}{ Dependents } & $0.0421^{* * *}$ & $0.0416^{* * *}$ & $0.0401 * * *$ \\
\hline & $(0.0134)$ & $(0.0136)$ & $(0.014)$ \\
\hline \multirow[t]{2}{*}{ Urban } & $0.1858^{* *}$ & $0.1901^{* *}$ & 0.1073 \\
\hline & $(0.0865)$ & $(0.0882)$ & $(0.0912)$ \\
\hline \multirow[t]{2}{*}{ Rainfall shock } & $-1.2578 * * *$ & $-1.2916^{* * *}$ & $-1.3037^{* * *}$ \\
\hline & $(0.2633)$ & $(0.272)$ & $(0.2679)$ \\
\hline \multirow[t]{2}{*}{ Infrastructural index } & $-0.0989 * * *$ & $-0.1005 * * *$ & $-0.0837 * * *$ \\
\hline & $(0.0318)$ & $(0.0326)$ & $(0.0325)$ \\
\hline \multirow[t]{2}{*}{ There is a bus stop in village? } & $0.1164 *$ & $0.1149^{*}$ & 0.0768 \\
\hline & $(0.0641)$ & $(0.0647)$ & $(0.0649)$ \\
\hline \multirow[t]{2}{*}{ Constant } & $-0.8735 * * *$ & $-0.8824 * * *$ & $-0.7678 * * *$ \\
\hline & $(0.2531)$ & $(0.2542)$ & $(0.2479)$ \\
\hline \multirow[t]{2}{*}{$\rho$} & $0.2198 * * *$ & $0.2218^{* * *}$ & $0.1951^{* * *}$ \\
\hline & $(0.0419)$ & $(0.0469)$ & $(0.0456)$ \\
\hline State FE & Yes & Yes & Yes \\
\hline Observations & 2,727 & 2,727 & 2,727 \\
\hline
\end{tabular}

(1) IDW matrix with at least 10 neighbors (2) IDW with all sample neighbors

(3) Wealth index controled: the index is constructed using principal-components analysis 
Table B.2 HERE

\section{Tables and Figures}

Table 1: Diversification strategies of farming households

\begin{tabular}{|c|c|c|c|}
\hline 2010-2011 & Nigeria & North & South \\
\hline Nonfarm enterprise (1) & 34.2 & 38.2 & 27.8 \\
\hline Non farm wage (2) & 2.4 & 2.4 & 2.5 \\
\hline Farm wage (3) & 2.4 & 3.0 & 1.5 \\
\hline Commercial crops (4) & 5.8 & 3.0 & 10.3 \\
\hline $\mathrm{n} 12$ & 4.2 & 4.4 & 3.7 \\
\hline n13 & 0.7 & 0.9 & 0.3 \\
\hline n14 & 6.1 & 4.1 & 9.4 \\
\hline $\mathrm{n} 23$ & 0.5 & 0.3 & 0.7 \\
\hline $\mathrm{n} 24$ & 0.5 & 0.2 & 1.1 \\
\hline n34 & 0.5 & 0.5 & 0.3 \\
\hline n123 & 2.2 & 2.1 & 2.4 \\
\hline n124 & 0.3 & 0.1 & 0.6 \\
\hline n134 & 0.3 & 0.1 & 0.5 \\
\hline n234 & 0.0 & 0.0 & 0.1 \\
\hline n1234 & 0.2 & 0.0 & 0.5 \\
\hline Farming only & 39.7 & 40.6 & 38.2 \\
\hline
\end{tabular}

Note: $\mathrm{n} 1$ refers to households who diversify only on NFE, n2 corresponds to non farm wage labor, $\mathrm{n} 3$ to farm wage labor, $\mathrm{n} 4$ to commercial cropping. For example, n124 refers to the percentage of farming households who diversify by having a NFE, and wage labor, and do commercial cropping.

Values are obtained using survey weights. Columns should add up to 100. 
Table 2: Summary statistics

$\begin{array}{lll}\text { Nigeria means } & \text { Northern means } & \text { Southern means }\end{array}$

\begin{tabular}{|c|c|c|c|c|c|c|c|c|c|c|c|c|}
\hline Variables & Nigeria & $\neg$ Diversified & Diversified & & North & $\neg$ Diversified & Diversified & & South & $\neg$ Diversified & Diversified & \\
\hline Nat. log of hectares owned & -0.856 & -0.930 & -0.807 & $*$ & -0.362 & -0.460 & -0.294 & $* *$ & -1.666 & -1.755 & -1.611 & \\
\hline Female headed & 0.109 & 0.142 & 0.088 & $* * *$ & 0.034 & 0.048 & 0.024 & $* *$ & 0.233 & 0.307 & 0.187 & $* * *$ \\
\hline Head's age & 50.631 & 51.338 & 50.160 & * & 47.160 & 47.704 & 46.782 & & 56.314 & 57.716 & 55.446 & ** \\
\hline Head is married & 0.870 & 0.820 & 0.904 & $* * *$ & 0.939 & 0.907 & 0.961 & $* * *$ & 0.758 & 0.666 & 0.814 & $* * *$ \\
\hline Head's educ. years & 4.589 & 3.758 & 5.142 & $* * *$ & 4.154 & 3.401 & 4.677 & $* * *$ & 5.302 & 4.384 & 5.870 & $* * *$ \\
\hline Adult females & 1.601 & 1.444 & 1.705 & $* * *$ & 1.612 & 1.420 & 1.745 & $* * *$ & 1.583 & 1.486 & 1.642 & ** \\
\hline Adult males & 1.380 & 1.270 & 1.454 & $* * *$ & 1.425 & 1.337 & 1.485 & $* * *$ & 1.308 & 1.152 & 1.404 & $* * *$ \\
\hline Dependents & 3.159 & 2.863 & 3.356 & $* * *$ & 3.670 & 3.222 & 3.981 & $* * *$ & 2.324 & 2.233 & 2.380 & \\
\hline Urban & 0.142 & 0.081 & 0.183 & $* * *$ & 0.110 & 0.061 & 0.143 & $* * *$ & 0.196 & 0.117 & 0.245 & $* * *$ \\
\hline Rainfall shock & -0.060 & -0.061 & -0.060 & & 0.012 & 0.010 & 0.014 & & -0.179 & -0.186 & -0.175 & \\
\hline Infrastructural constraint & 0 & 0.133 & -0.089 & $* * *$ & 0 & 0.0489 & -0.0339 & & 0 & -0.0171 & 0.0106 & \\
\hline Distance to nearest road $(\mathrm{km})$ & 16.665 & 18.333 & 15.556 & $* * *$ & 19.920 & 21.701 & 18.682 & $* * *$ & 11.335 & 12.422 & 10.663 & ** \\
\hline Distance to pop. center (km) & 24.311 & 24.852 & 23.951 & & 30.291 & 30.637 & 30.051 & & 14.520 & 14.698 & 14.409 & \\
\hline Distance to market $(\mathrm{km})$ & 70.400 & 70.085 & 70.609 & & 72.323 & 72.786 & 72.001 & & 67.250 & 65.343 & 68.431 & \\
\hline Distance to border post $(\mathrm{km})$ & 308.463 & 313.917 & 304.838 & & 233.396 & 234.590 & 232.566 & & 431.385 & 453.155 & 417.913 & $* * *$ \\
\hline Is there a bus stop in village? & 0.342 & 0.267 & 0.391 & $* * *$ & 0.364 & 0.257 & 0.438 & $* * *$ & 0.305 & 0.286 & 0.317 & \\
\hline Observations & 2,727 & 1,601 & 1,126 & & 1,700 & 989 & 711 & & 1,027 & 612 & 415 & \\
\hline
\end{tabular}

Statistical significance of the difference between the mean outcomes of the diversifying and non diversifying households: ${ }^{* * *} \mathrm{p}<0.01,{ }^{* *} \mathrm{p}<0.05,{ }^{*} \mathrm{p}<0.1$ 
Table 3: Probit results on diversification

Nigeria

\begin{tabular}{|c|c|c|c|c|}
\hline & Spatial & Standard & Spatial & Standard \\
\hline Variables & Diversified & Diversified & Diversified & Diversified \\
\hline \multirow[t]{2}{*}{ Nat. log of hectares owned } & -0.0017 & 0.0208 & 0.0039 & 0.0165 \\
\hline & $(0.0169)$ & $(0.0233)$ & $(0.0221)$ & $(0.0252)$ \\
\hline \multirow[t]{2}{*}{ Female headed } & 0.1276 & 0.118 & 0.1072 & 0.104 \\
\hline & $(0.1365)$ & $(0.149)$ & $(0.1463)$ & $(0.150)$ \\
\hline \multirow[t]{2}{*}{ Head's age } & $-0.0046^{* *}$ & -0.00360 & $-0.0082^{* * *}$ & $-0.00772^{* * *}$ \\
\hline & $(0.0019)$ & $(0.00229)$ & $(0.002)$ & $(0.00240)$ \\
\hline \multirow[t]{2}{*}{ Head is married } & $0.43^{* * *}$ & $0.344^{* *}$ & $0.3843^{* * *}$ & $0.316 * *$ \\
\hline & $(0.1196)$ & $(0.135)$ & $(0.1248)$ & $(0.145)$ \\
\hline \multirow[t]{2}{*}{ Head's educ. years } & $0.0243^{* * *}$ & $0.0280 * * *$ & $0.0237 * * *$ & $0.0249 * * *$ \\
\hline & $(0.0055)$ & $(0.00682)$ & $(0.0061)$ & $(0.00697)$ \\
\hline \multirow[t]{2}{*}{ Adult females } & $0.1064 * * *$ & $0.130^{* * *}$ & $0.1403 * * *$ & $0.159^{* * *}$ \\
\hline & $(0.0305)$ & $(0.0390)$ & $(0.0322)$ & $(0.0397)$ \\
\hline \multirow[t]{2}{*}{ Adult males } & $0.0602^{*}$ & $0.0673^{*}$ & $0.1109^{* * *}$ & $0.109^{* * *}$ \\
\hline & $(0.0307)$ & $(0.0376)$ & $(0.0332)$ & $(0.0372)$ \\
\hline \multirow[t]{2}{*}{ Dependents } & $0.0331 * * *$ & $0.0386 * *$ & $0.0421 * * *$ & $0.0477^{* * *} *$ \\
\hline & $(0.0127)$ & $(0.0156)$ & $(0.0134)$ & $(0.0145)$ \\
\hline \multirow[t]{2}{*}{ Urban } & $0.2894^{* * *}$ & $0.467 * * *$ & $0.1916^{* *}$ & $0.232^{*}$ \\
\hline & $(0.0741)$ & $(0.129)$ & $(0.0867)$ & $(0.119)$ \\
\hline \multirow[t]{2}{*}{ Rainfall shock } & 0.0542 & -0.200 & $-1.2729 * * *$ & $-1.857^{* * *}$ \\
\hline & $(0.1546)$ & $(0.289)$ & $(0.264)$ & $(0.384)$ \\
\hline \multirow[t]{2}{*}{ Infrastructural index } & $-0.0479 *$ & -0.0324 & $-0.0992^{* * *}$ & $-0.0965^{* *}$ \\
\hline & $(0.0247)$ & $(0.0480)$ & $(0.0319)$ & $(0.0491)$ \\
\hline \multirow[t]{2}{*}{ There is a bus stop in village? } & 0.0784 & $0.196^{* *}$ & $0.1163^{*}$ & $0.181^{* *}$ \\
\hline & $(0.0495)$ & $(0.0889)$ & $(0.0643)$ & $(0.0883)$ \\
\hline \multirow[t]{2}{*}{ Constant } & $-0.5516^{* * *}$ & $-0.533^{* * *}$ & $-0.8794^{* * *}$ & $-1.156^{* * *}$ \\
\hline & $(0.1521)$ & $(0.190)$ & $(0.2533)$ & $(0.294)$ \\
\hline \multirow[t]{2}{*}{$\rho$} & $0.4923^{* * *}$ & & $0.2225 * * *$ & \\
\hline & $(0.0298)$ & & $(0.044)$ & \\
\hline State FE & No & No & Yes & Yes \\
\hline Observations & 2,727 & 2,727 & 2,727 & 2,727 \\
\hline
\end{tabular}

Standard errors in parentheses. Spatial probit: 8,004 draws, 1,992 burn-in *** $\mathrm{p}<0.01, * * \mathrm{p}<0.05, * \mathrm{p}<0.1$ 
Table 4: Probit results on diversification Marginal Effects

\begin{tabular}{|c|c|c|c|c|c|c|c|c|}
\hline \multirow[b]{3}{*}{ Variables } & \multicolumn{8}{|c|}{ Nigeria } \\
\hline & Spatial & Spatial & Spatial & Standard & Spatial & Spatial & Spatial & Standard \\
\hline & Div. (direct) & Div. (indirect) & Div. (total) & Diversified & Div. (direct) & Div. (indirect) & Div. (total) & Diversified \\
\hline \multirow[t]{2}{*}{ Nat. log of hectares owned } & -0.001436 & -0.001196 & -0.002632 & 0.00798 & 0.001584 & 0.0004312 & 0.0020152 & 0.00624 \\
\hline & {$[-0.011534,0.009]$} & {$[-0.009727,0.008]$} & {$[-0.021069,0.016]$} & $(0.00894)$ & {$[-0.0102114,0.013]$} & {$[-0.002797,0.004]$} & {$[-0.0130058,0.017]$} & $(0.00952)$ \\
\hline \multirow[t]{2}{*}{ Female headed } & 0.049062 & 0.042071 & 0.091134 & 0.0445 & 0.0358388 & 0.009723 & 0.0455616 & 0.0387 \\
\hline & {$[-0.039667,0.137]$} & {$[-0.034423,0.123]$} & {$[-0.072459,0.259]$} & $(0.0554)$ & {$[-0.0432074,0.116]$} & {$[-0.01205,0.033]$} & {$[-0.0562402,0.143]$} & $(0.0553)$ \\
\hline \multirow[t]{2}{*}{ Head's age } & -0.001797 & -0.001527 & -0.003324 & -0.00138 & -0.0025884 & -0.000719 & -0.0033074 & $-0.00293^{* * *}$ \\
\hline & {$[-0.00302,-0.001]$} & {$[-0.002628,0]$} & {$[-0.005579,-0.001]$} & $(0.000878)$ & {$[-0.0036453,-0.002]$} & {$[-0.001129,0]$} & {$[-0.0046445,-0.002]$} & $(0.000909)$ \\
\hline \multirow[t]{2}{*}{ Head is married } & 0.161281 & 0.137394 & 0.298675 & $0.135^{* *}$ & 0.1216651 & 0.03365 & 0.155316 & $0.123^{* *}$ \\
\hline & {$[0.087213,0.233]$} & {$[0.07107,0.211]$} & {$[0.159783,0.438]$} & $(0.0536)$ & {$[0.0523872,0.185]$} & {$[0.01321,0.058]$} & {$[0.0688851,0.24]$} & $(0.0572)$ \\
\hline \multirow[t]{2}{*}{ Head's educ. years } & 0.009276 & 0.007874 & 0.01715 & $0.0108^{* * *}$ & 0.0076997 & 0.002129 & 0.0098288 & $0.00943^{* * *}$ \\
\hline & {$[0.005732,0.013]$} & {$[0.00477,0.011]$} & {$[0.010677,0.024]$} & $(0.00263)$ & {$[0.0043115,0.011]$} & {$[0.001021,0.003]$} & {$[0.0055941,0.014]$} & $(0.00264)$ \\
\hline \multirow[t]{2}{*}{ Adult females } & 0.041907 & 0.035593 & 0.0775 & $0.0498^{* * *}$ & 0.0461035 & 0.01277 & 0.0588737 & $0.0603^{* * *}$ \\
\hline & {$[0.021348,0.062]$} & {$[0.017657,0.055]$} & {$[0.038945,0.117]$} & $(0.0150)$ & {$[0.0288284,0.064]$} & {$[0.006396,0.02]$} & {$[0.0363946,0.083]$} & $(0.0150)$ \\
\hline \multirow[t]{2}{*}{ Adult males } & 0.023921 & 0.02035 & 0.044271 & $0.0259^{*}$ & 0.0347585 & 0.0097 & 0.0444585 & $0.0415^{* * *}$ \\
\hline & {$[0.004381,0.045]$} & {$[0.003782,0.04]$} & {$[0.007968,0.083]$} & $(0.0144)$ & {$[0.0185825,0.052]$} & {$[0.004213,0.016]$} & {$[0.0233077,0.066]$} & $(0.0141)$ \\
\hline \multirow[t]{2}{*}{ Dependents } & 0.012868 & 0.010927 & 0.023795 & $0.0148^{* *}$ & 0.0132649 & 0.003698 & 0.0169634 & $0.0181^{* * *}$ \\
\hline & {$[0.004516,0.021]$} & {$[0.003775,0.018]$} & {$[0.008204,0.039]$} & $(0.00596)$ & {$[0.0058452,0.02]$} & {$[0.001418,0.007]$} & {$[0.0075651,0.027]$} & $(0.00547)$ \\
\hline \multirow[t]{2}{*}{ Urban } & 0.109176 & 0.092693 & 0.20187 & $0.168^{* * *}$ & 0.0588006 & 0.01634 & 0.0751384 & $0.0851^{* *}$ \\
\hline & {$[0.067048,0.153]$} & {$[0.055113,0.136]$} & {$[0.123323,0.288]$} & $(0.0422)$ & {$[0.0118077,0.102]$} & {$[0.002893,0.03]$} & {$[0.0151353,0.13]$} & $(0.0419)$ \\
\hline \multirow[t]{2}{*}{ Rainfall shock } & 0.01989 & 0.016676 & 0.036566 & -0.0768 & -0.405545 & -0.1121 & -0.5176015 & $-0.703^{* * *}$ \\
\hline & {$[-0.080591,0.119]$} & {$[-0.067813,0.106]$} & {$[-0.151099,0.225]$} & $(0.111)$ & {$[-0.5379631,-0.276]$} & {$[-0.1742,-0.059]$} & {$[-0.6865748,-0.353]$} & $(0.145)$ \\
\hline \multirow[t]{2}{*}{ Infrastructural constraint } & -0.018129 & -0.015321 & -0.03345 & -0.0124 & -0.0317012 & -0.008754 & -0.0404554 & $-0.0366^{* *}$ \\
\hline & {$[-0.034532,-0.002]$} & {$[-0.028588,-0.002]$} & {$[-0.062058,-0.004]$} & $(0.0184)$ & {$[-0.0469901,-0.016]$} & {$[-0.01464,-0.004]$} & {$[-0.060951,-0.021]$} & $(0.0186)$ \\
\hline \multirow[t]{2}{*}{ There is a bus stop in village? } & 0.030744 & 0.026056 & 0.056799 & $0.0745^{* *}$ & 0.0371397 & 0.01024 & 0.0473778 & $0.0676^{* *}$ \\
\hline & {$[0.002268,0.061]$} & {$[0.001973,0.052]$} & {$[0.004208,0.113]$} & $(0.0335)$ & {$[0.0027744,0.074]$} & {$[0.0007777,0.022]$} & {$[0.0034577,0.092]$} & $(0.0327)$ \\
\hline
\end{tabular}

\begin{tabular}{|c|c|c|c|c|c|c|c|c|}
\hline State FE & No & No & No & No & Yes & Yes & Yes & Yes \\
\hline Observations & 2,727 & 2,727 & 2,727 & 2,727 & 2,727 & 2,727 & 2,727 & 2,727 \\
\hline
\end{tabular}

$95 \%$ confidence interval estimates in brackets; standard errors estimates in parentheses

${ }^{* * *} \mathrm{p}<0.01, * * \mathrm{p}<0.05, * \mathrm{p}<0.1$, only for standard probit. 
Table 5: Probit results on diversification North

\section{Nigeria-North}

\begin{tabular}{|c|c|c|c|c|}
\hline & Spatial & Standard & Spatial & Standard \\
\hline Variables & Diversified & Diversified & Diversified & Diversified \\
\hline \multirow[t]{2}{*}{ Nat. log of hectares owned } & 0.0376 & $0.0604^{*}$ & 0.0081 & 0.0125 \\
\hline & $(0.0254)$ & $(0.0343)$ & $(0.0291)$ & $(0.0339)$ \\
\hline \multirow[t]{2}{*}{ Female headed } & 0.0888 & 0.0633 & 0.0996 & 0.0817 \\
\hline & $(0.2475)$ & $(0.265)$ & $(0.2531)$ & $(0.277)$ \\
\hline \multirow[t]{2}{*}{ Head's age } & $-0.0071 * * *$ & $-0.00616^{*}$ & $-0.0069 * * *$ & $-0.00657^{* *}$ \\
\hline & $(0.0025)$ & (0.00329) & $(0.0026)$ & (0.00318) \\
\hline \multirow[t]{2}{*}{ Head is married } & $0.4177^{* *}$ & 0.254 & $0.4007^{* *}$ & 0.288 \\
\hline & $(0.1887)$ & $(0.229)$ & $(0.1922)$ & $(0.250)$ \\
\hline \multirow[t]{2}{*}{ Head's educ. years } & $0.0216^{* * *}$ & $0.0274^{* * *}$ & $0.0267^{* * *}$ & $0.0303^{* * *}$ \\
\hline & $(0.007)$ & $(0.00894)$ & $(0.0075)$ & $(0.00842)$ \\
\hline \multirow[t]{2}{*}{ Adult females } & $0.162 * * *$ & $0.198 * * *$ & $0.1953^{* * *}$ & $0.211 * * *$ \\
\hline & $(0.0426)$ & $(0.0541)$ & $(0.0458)$ & $(0.0562)$ \\
\hline \multirow[t]{2}{*}{ Adult males } & 0.0453 & 0.0519 & 0.0641 & 0.0717 \\
\hline & $(0.0413)$ & $(0.0463)$ & $(0.0437)$ & $(0.0455)$ \\
\hline \multirow[t]{2}{*}{ Dependents } & $0.0504^{* * *}$ & $0.0583^{* * *}$ & $0.0393 * *$ & $0.0490^{* * *}$ \\
\hline & $(0.0155)$ & $(0.0178)$ & $(0.0163)$ & $(0.0171)$ \\
\hline \multirow[t]{2}{*}{ Urban } & $0.1945 *$ & $0.395^{* *}$ & 0.1648 & 0.290 \\
\hline & $(0.107)$ & $(0.198)$ & $(0.1213)$ & $(0.178)$ \\
\hline \multirow[t]{2}{*}{ Rainfall shock } & 0.0786 & 0.0591 & $-1.0905 * * *$ & $-1.711^{* * *}$ \\
\hline & $(0.1952)$ & $(0.352)$ & $(0.2896)$ & $(0.441)$ \\
\hline \multirow[t]{2}{*}{ Infrastructural constraint } & -0.0335 & -0.00963 & $-0.0698 * *$ & -0.0653 \\
\hline & $(0.0226)$ & $(0.0431)$ & $(0.0288)$ & $(0.0440)$ \\
\hline \multirow[t]{2}{*}{ There is a bus stop in village? } & $0.1777^{* * *}$ & $0.409 * * *$ & $0.2096 * * *$ & $0.347^{* * *}$ \\
\hline & $(0.0627)$ & $(0.116)$ & $(0.0792)$ & $(0.122)$ \\
\hline \multirow[t]{2}{*}{ Constant } & $-0.6006 * * *$ & $-0.587^{* *}$ & $-1.2673^{* * *}$ & $-1.484^{* * *}$ \\
\hline & $(0.2127)$ & $(0.251)$ & $(0.2547)$ & $(0.295)$ \\
\hline \multirow[t]{2}{*}{$\rho$} & $0.4981^{* * *}$ & & $0.2991 * * *$ & \\
\hline & $(0.0363)$ & & $(0.0501)$ & \\
\hline State FE & No & No & Yes & Yes \\
\hline Observations & 1,700 & 1,700 & 1,700 & 1,700 \\
\hline
\end{tabular}

Standard errors in parentheses. Spatial probit: 8,004 draws, 1,992 burn-in *** $\mathrm{p}<0.01, * * \mathrm{p}<0.05, * \mathrm{p}<0.1$ 
Table 6: Probit results on diversification Marginal Effects

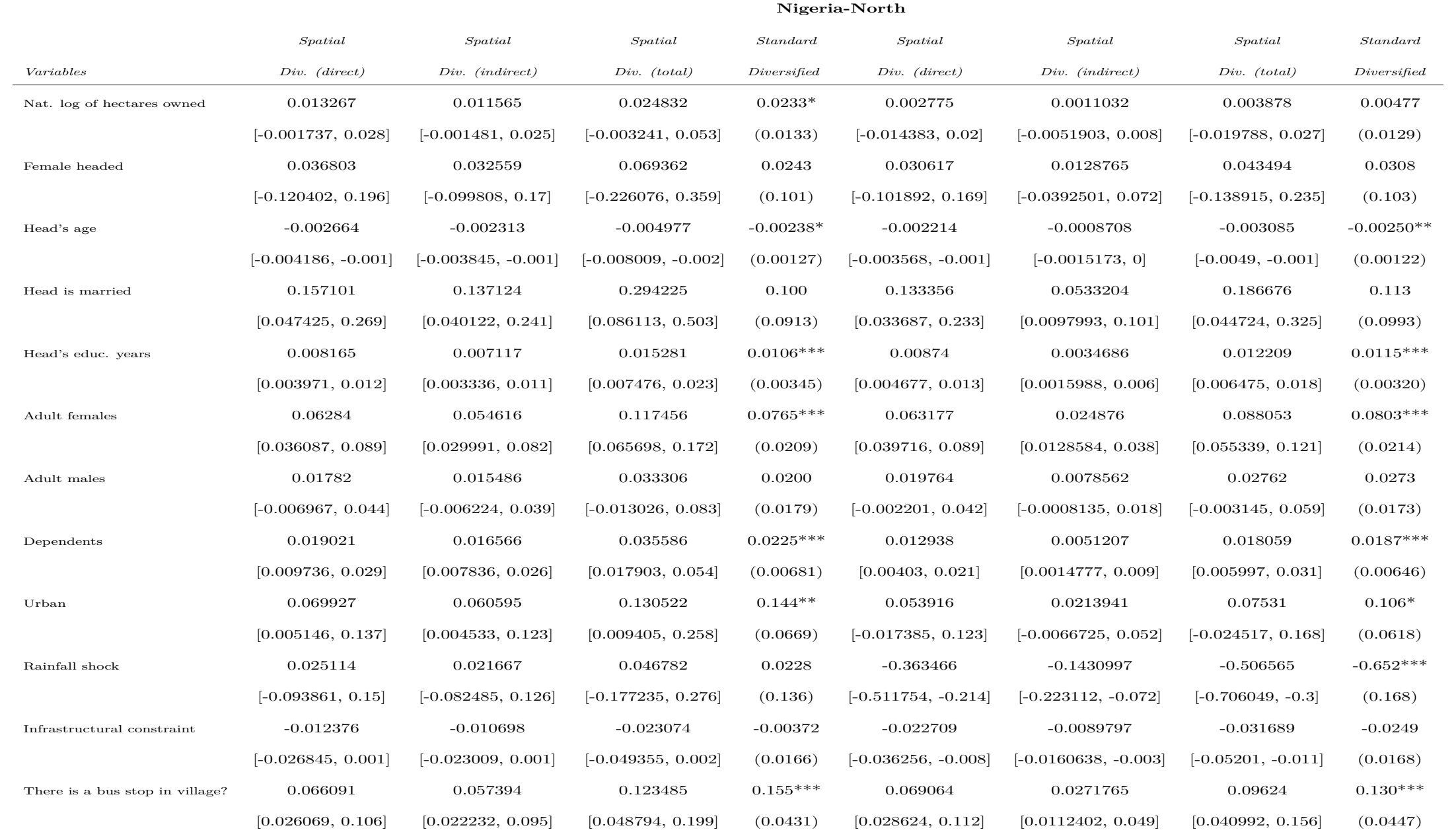

\begin{tabular}{|c|c|c|c|c|c|c|c|c|}
\hline State FE & No & No & No & No & Yes & Yes & Yes & Yes \\
\hline Observations & 1,700 & 1,700 & 1,700 & 1,700 & 1,700 & 1,700 & 1,700 & 1,700 \\
\hline
\end{tabular}

$95 \%$ confidence interval estimates in brackets; standard errors estimates in parentheses

${ }^{* * *} \mathrm{p}<0.01,{ }^{* *} \mathrm{p}<0.05, * \mathrm{p}<0.1$. 
Table 7: Probit results on diversification South

\section{Nigeria-South}

\begin{tabular}{|c|c|c|c|c|}
\hline & Spatial & Standard & Spatial & Standard \\
\hline Variables & Diversified & Diversified & Diversified & Diversified \\
\hline \multirow[t]{2}{*}{ Nat. log of hectares owned } & -0.0278 & -0.00559 & 0.0075 & 0.0251 \\
\hline & $(0.025)$ & $(0.0306)$ & $(0.0347)$ & $(0.0371)$ \\
\hline \multirow[t]{2}{*}{ Female headed } & 0.104 & 0.111 & 0.1426 & 0.115 \\
\hline & $(0.1734)$ & $(0.172)$ & $(0.1815)$ & $(0.182)$ \\
\hline \multirow[t]{2}{*}{ Head's age } & -0.0044 & -0.00459 & $-0.0123 * * *$ & $-0.0118 * * *$ \\
\hline & $(0.0032)$ & (0.00358) & $(0.0035)$ & $(0.00384)$ \\
\hline \multirow[t]{2}{*}{ Head is married } & $0.4789^{* * *}$ & $0.453^{* * *}$ & $0.3944^{* *}$ & $0.332^{*}$ \\
\hline & $(0.1589)$ & $(0.167)$ & $(0.1638)$ & $(0.176)$ \\
\hline \multirow[t]{2}{*}{ Head's educ. years } & $0.0244^{* * *}$ & $0.0230 * *$ & 0.017 & 0.0136 \\
\hline & $(0.0095)$ & $(0.0114)$ & $(0.0106)$ & $(0.0120)$ \\
\hline \multirow[t]{2}{*}{ Adult females } & 0.0388 & 0.0598 & 0.0719 & $0.104^{* *}$ \\
\hline & $(0.0437)$ & $(0.0536)$ & $(0.0459)$ & $(0.0518)$ \\
\hline \multirow[t]{2}{*}{ Adult males } & $0.0852^{*}$ & 0.0939 & $0.1761 * * *$ & $0.155 * *$ \\
\hline & $(0.0487)$ & $(0.0604)$ & $(0.0523)$ & $(0.0631)$ \\
\hline \multirow[t]{2}{*}{ Dependents } & -0.0181 & -0.0155 & 0.0353 & 0.0315 \\
\hline & $(0.0239)$ & $(0.0294)$ & $(0.026)$ & $(0.0305)$ \\
\hline \multirow[t]{2}{*}{ Urban } & $0.3924 * * *$ & $0.573^{* * *}$ & $0.2375^{*}$ & 0.173 \\
\hline & $(0.1068)$ & $(0.146)$ & $(0.1401)$ & $(0.149)$ \\
\hline \multirow[t]{2}{*}{ Rainfall shock } & $0.8532^{* *}$ & 0.164 & $-2.1653^{* * *}$ & $-2.461 * * *$ \\
\hline & $(0.3895)$ & $(0.682)$ & $(0.6657)$ & $(0.655)$ \\
\hline \multirow[t]{2}{*}{ Infrastructural constraint } & -0.0222 & 0.0182 & $-0.1503^{* * *}$ & $-0.139 * *$ \\
\hline & $(0.0341)$ & $(0.0579)$ & $(0.0567)$ & $(0.0695)$ \\
\hline \multirow[t]{2}{*}{ There is a bus stop in village? } & -0.0866 & -0.111 & -0.1223 & -0.0587 \\
\hline & $(0.0882)$ & $(0.131)$ & $(0.1168)$ & $(0.114)$ \\
\hline \multirow[t]{2}{*}{ Constant } & -0.1744 & -0.152 & $-0.7315^{* *}$ & $-0.835 *$ \\
\hline & $(0.2571)$ & $(0.388)$ & $(0.372)$ & $(0.439)$ \\
\hline \multirow[t]{2}{*}{$\rho$} & $0.4039 * * *$ & & -0.0236 & \\
\hline & $(0.0565)$ & & $(0.0869)$ & \\
\hline State FE & No & No & Yes & Yes \\
\hline Observations & 1,027 & 1,027 & 1,027 & 1,027 \\
\hline
\end{tabular}

Standard errors in parentheses. Spatial probit: 8,004 draws, 1,992 burn-in *** $\mathrm{p}<0.01, * * \mathrm{p}<0.05, * \mathrm{p}<0.1$ 
Table 8: Probit results on diversification Marginal Effects

\begin{tabular}{|c|c|c|c|c|c|c|c|c|}
\hline \multirow[b]{3}{*}{ Variables } & \multicolumn{8}{|c|}{ Nigeria-South } \\
\hline & Spatial & Spatial & Spatial & Standard & Spatial & Spatial & Spatial & Standard \\
\hline & Div. (direct) & Div. (indirect) & Div. (total) & Diversified & Div. (direct) & Div. (indirect) & Div. (total) & Diversified \\
\hline \multirow[t]{2}{*}{ Nat. log of hectares owned } & -0.010513 & -0.010513 & -0.0171 & -0.00212 & 0.0016404 & -0.00006948 & 0.0015709 & 0.00934 \\
\hline & {$[-0.025772,0.004]$} & {$[-0.025772,0.004]$} & {$[-0.041082,0.007]$} & $(0.0116)$ & {$[-0.0166048,0.02]$} & {$[-0.001629,0.001]$} & {$[-0.0158112,0.019]$} & $(0.0139)$ \\
\hline \multirow[t]{2}{*}{ Female headed } & 0.039468 & 0.039468 & 0.064861 & 0.0417 & 0.0490837 & -0.0008433 & 0.0482404 & 0.0422 \\
\hline & {$[-0.068969,0.146]$} & {$[-0.068969,0.146]$} & {$[-0.111874,0.233]$} & $(0.0638)$ & {$[-0.0436633,0.139]$} & {$[-0.01163,0.009]$} & {$[-0.0407708,0.139]$} & $(0.0663)$ \\
\hline \multirow[t]{2}{*}{ Head's age } & -0.001634 & -0.001634 & -0.002673 & -0.00174 & -0.0038147 & 0.00007037 & -0.0037443 & $-0.00439 * * *$ \\
\hline & {$[-0.003515,0]$} & {$[-0.003515,0]$} & {$[-0.00598,0.001]$} & $(0.00135)$ & {$[-0.0055066,-0.002]$} & {$[-0.0004849,0.001]$} & {$[-0.0054457,-0.002]$} & $(0.00142)$ \\
\hline \multirow[t]{2}{*}{ Head is married } & 0.174268 & 0.174268 & 0.284547 & $0.176^{* * *}$ & 0.1248323 & -0.002284 & 0.1225488 & $0.127^{*}$ \\
\hline & {$[0.088186,0.265]$} & {$[0.088186,0.265]$} & {$[0.139585,0.445]$} & $(0.0653)$ & {$[0.0455985,0.207]$} & {$[-0.02157,0.017]$} & {$[0.0445372,0.208]$} & $(0.0683)$ \\
\hline \multirow[t]{2}{*}{ Head's educ. years } & 0.008954 & 0.008954 & 0.014576 & $0.00873^{* *}$ & 0.0048379 & -0.0001 & 0.0047379 & 0.00506 \\
\hline & {$[0.003176,0.015]$} & {$[0.003176,0.015]$} & {$[0.005133,0.024]$} & $(0.00437)$ & {$[-0.0005676,0.01]$} & {$[-0.0009615,0.001]$} & {$[-0.0005827,0.01]$} & $(0.00451)$ \\
\hline \multirow[t]{2}{*}{ Adult females } & 0.015331 & 0.015331 & 0.024947 & 0.0227 & 0.0215579 & -0.0003906 & 0.0211674 & $0.0387 * *$ \\
\hline & {$[-0.011658,0.042]$} & {$[-0.011658,0.042]$} & {$[-0.020343,0.068]$} & $(0.0203)$ & {$[-0.000557,0.044]$} & {$[-0.004005,0.003]$} & {$[-0.0005517,0.044]$} & $(0.0193)$ \\
\hline \multirow[t]{2}{*}{ Adult males } & 0.03161 & 0.03161 & 0.051613 & 0.0356 & 0.0550869 & -0.0009723 & 0.0541146 & $0.0578^{* *}$ \\
\hline & {$[0.003095,0.062]$} & {$[0.003095,0.062]$} & {$[0.005095,0.1]$} & $(0.0229)$ & {$[0.0308641,0.081]$} & {$[-0.009713,0.007]$} & {$[0.0296075,0.08]$} & $(0.0234)$ \\
\hline \multirow[t]{2}{*}{ Dependents } & -0.006654 & -0.006654 & -0.01072 & -0.00588 & 0.0106356 & -0.0001648 & 0.0104708 & 0.0118 \\
\hline & {$[-0.020879,0.007]$} & {$[-0.020879,0.007]$} & {$[-0.032843,0.012]$} & $(0.0111)$ & {$[-0.0026025,0.023]$} & {$[-0.002271,0.002]$} & {$[-0.0024557,0.023]$} & $(0.0114)$ \\
\hline \multirow[t]{2}{*}{ Urban } & 0.143371 & 0.143371 & 0.233196 & $0.200^{* * *}$ & 0.0731698 & -0.00128 & 0.0718897 & 0.0633 \\
\hline & {$[0.080257,0.205]$} & {$[0.080257,0.205]$} & {$[0.129888,0.338]$} & $(0.0459)$ & {$[0.0080046,0.142]$} & {$[-0.01395,0.01]$} & {$[0.0074528,0.14]$} & $(0.0530)$ \\
\hline \multirow[t]{2}{*}{ Rainfall shock } & 0.306558 & 0.306558 & 0.498848 & 0.0620 & -0.6734967 & 0.01459 & -0.6589075 & $-0.918^{* * *}$ \\
\hline & {$[0.062991,0.556]$} & {$[0.062991,0.556]$} & {$[0.09914,0.907]$} & $(0.258)$ & {$[-0.9963934,-0.32]$} & {$[-0.07989,0.119]$} & {$[-0.9667467,-0.318]$} & $(0.239)$ \\
\hline \multirow[t]{2}{*}{ Infrastructural constraint } & -0.007748 & -0.007748 & -0.012512 & 0.00690 & -0.0461649 & 0.0008703 & -0.0452946 & $-0.0519^{* *}$ \\
\hline & {$[-0.029448,0.012]$} & {$[-0.029448,0.012]$} & {$[-0.045732,0.019]$} & $(0.0219)$ & {$[-0.0741727,-0.018]$} & {$[-0.005973,0.009]$} & {$[-0.0757397,-0.018]$} & $(0.0257)$ \\
\hline \multirow[t]{2}{*}{ There is a bus stop in village? } & -0.031081 & -0.031081 & -0.050748 & -0.0421 & -0.0336185 & 0.0002396 & -0.0333789 & -0.0220 \\
\hline & {$[-0.083866,0.021]$} & {$[-0.083866,0.021]$} & {$[-0.139793,0.032]$} & $(0.0501)$ & {$[-0.090933,0.021]$} & {$[-0.006843,0.007]$} & {$[-0.0895277,0.021]$} & $(0.0428)$ \\
\hline
\end{tabular}

\begin{tabular}{|c|c|c|c|c|c|c|c|c|}
\hline State $\mathrm{FE}$ & No & No & No & No & Yes & Yes & Yes & Yes \\
\hline Observations & 1,027 & 1,027 & 1,027 & 1,027 & 1,027 & 1,027 & 1,027 & 1,027 \\
\hline
\end{tabular}

$95 \%$ confidence interval estimates in brackets; standard errors estimates in parentheses

${ }^{* * *} \mathrm{p}<0.01,{ }^{* *} \mathrm{p}<0.05,{ }^{*} \mathrm{p}<0.1$. 
Table 9: diversification by activity, SAR probit estimates, Nigeria

Nigeria

Non-farm diversification

Farm diversification

\begin{tabular}{|c|c|c|c|c|}
\hline Variables & NFE \& Non-farm Wage & $N F E$ & Comm.crop ${ }^{a}$ \& Farm Wage & Comm.crop ${ }^{a}$ \\
\hline \multirow[t]{2}{*}{ Nat. log of hectares owned } & -0.0222 & -0.0021 & $0.0801^{* * *}$ & $0.162^{* * *}$ \\
\hline & $(0.0223)$ & $(0.0221)$ & $(0.0271)$ & $(0.0331)$ \\
\hline \multirow[t]{2}{*}{ Female headed } & 0.0905 & 0.0915 & 0.0242 & -0.0115 \\
\hline & $(0.1504)$ & $(0.1505)$ & $(0.1696)$ & $(0.191)$ \\
\hline \multirow[t]{2}{*}{ Head's age } & $-0.01^{* * *}$ & $-0.0107^{* * *}$ & -0.0009 & 0.0013 \\
\hline & $(0.0021)$ & $(0.0021)$ & $(0.0025)$ & $(0.003)$ \\
\hline \multirow[t]{2}{*}{ Head is married } & $0.4499^{* * *}$ & $0.4531^{* * *}$ & 0.1511 & -0.0446 \\
\hline & $(0.1291)$ & $(0.1297)$ & $(0.1495)$ & $(0.1702)$ \\
\hline \multirow[t]{2}{*}{ Head's educ. years } & $0.0267^{* * *}$ & 0.0078 & -0.001 & 0.0119 \\
\hline & $(0.0061)$ & $(0.006)$ & $(0.0071)$ & $(0.0084)$ \\
\hline \multirow[t]{2}{*}{ Adult females } & $0.1655^{* * *}$ & $0.1402^{* * *}$ & $0.0805^{* *}$ & 0.0171 \\
\hline & $(0.0324)$ & $(0.032)$ & $(0.0363)$ & $(0.0448)$ \\
\hline \multirow[t]{2}{*}{ Adult males } & $0.1204^{* * *}$ & $0.079^{* *}$ & 0.0412 & -0.052 \\
\hline & $(0.0331)$ & $(0.0324)$ & $(0.0369)$ & $(0.0474)$ \\
\hline \multirow[t]{2}{*}{ Dependents } & $0.0454^{* * *}$ & $0.0485^{* * *}$ & 0.0026 & 0.0253 \\
\hline & $(0.0135)$ & $(0.0133)$ & $(0.0154)$ & $(0.0187)$ \\
\hline \multirow[t]{2}{*}{ Urban } & $0.2555^{* * *}$ & $0.2686^{* * *}$ & -0.0981 & -0.1027 \\
\hline & $(0.0855)$ & $(0.0834)$ & $(0.0928)$ & $(0.1066)$ \\
\hline \multirow[t]{2}{*}{ Rainfall shock } & $-1.1666^{* * *}$ & $-1.1423^{* * *}$ & $-0.7169^{* *}$ & -0.3689 \\
\hline & $(0.2681)$ & $(0.2659)$ & $(0.2931)$ & $(0.3274)$ \\
\hline \multirow[t]{2}{*}{ Infrastructural index } & $-0.14^{* * *}$ & $-0.1425^{* * *}$ & 0.0288 & 0.0404 \\
\hline & $(0.0331)$ & $(0.0331)$ & $(0.0362)$ & $(0.0461)$ \\
\hline \multirow[t]{2}{*}{ There is a bus stop in village? } & $0.1833^{* * *}$ & $0.1586^{* *}$ & -0.0797 & 0.0134 \\
\hline & $(0.0658)$ & $(0.065)$ & $(0.0704)$ & $(0.077)$ \\
\hline \multirow[t]{2}{*}{ Constant } & $-1.1827^{* * *}$ & $-1.0391^{* * *}$ & $-0.9755^{* * *}$ & -0.514 \\
\hline & $(0.2606)$ & $(0.262)$ & $(0.3011)$ & $(0.3262)$ \\
\hline \multirow[t]{2}{*}{$\rho$} & $0.2034^{* * *}$ & $0.2097^{* * *}$ & $0.3546^{* * *}$ & $0.4543^{* * *}$ \\
\hline & $(0.0447)$ & $(0.0453)$ & $(0.0514)$ & $(0.0492)$ \\
\hline State FE & Yes & Yes & Yes & Yes \\
\hline Observations & 2,727 & 2,727 & 2,727 & 2,727 \\
\hline
\end{tabular}

Standard errors in parentheses. Spatial probit: 8,004 draws, 1,992 burn-in $\left(* * * \mathrm{p}<0.01,{ }^{* *} \mathrm{p}<0.05,{ }^{*} \mathrm{p}<0.1\right)$

a) Non-farm enterprise; b) Cash cropping 
Table 10: diversification by activity, SAR probit estimates, North

Nigeria-North

\begin{tabular}{|c|c|c|c|c|c|}
\hline \multirow[b]{2}{*}{ Variables } & \multicolumn{3}{|c|}{ Non-farm diversification } & \multicolumn{2}{|c|}{ Farm diversification } \\
\hline & $N F E^{a}$ & $\&$ Non-farm Wage & $N F E^{a}$ & Comm.crop ${ }^{b}$ \& Farm Wage & Comm.crop ${ }^{b}$ \\
\hline \multirow[t]{2}{*}{ Nat. $\log$ of hectares owned } & & 0.0038 & 0.0163 & 0.034 & $0.0988 * *$ \\
\hline & & $(0.0295)$ & $(0.0292)$ & $(0.0376)$ & $(0.0488)$ \\
\hline \multirow[t]{2}{*}{ Female headed } & & 0.2465 & 0.1642 & -0.0497 & -0.349 \\
\hline & & $(0.2882)$ & $(0.2951)$ & $(0.3324)$ & $(0.3928)$ \\
\hline \multirow[t]{2}{*}{ Head's age } & & $-0.006^{* *}$ & $-0.0063^{* *}$ & -0.0057 & -0.0054 \\
\hline & & $(0.0027)$ & $(0.0027)$ & $(0.0035)$ & $(0.0044)$ \\
\hline \multirow[t]{2}{*}{ Head is married } & & $0.6271^{* * *}$ & $0.6244^{* * *}$ & 0.2081 & -0.3864 \\
\hline & & $(0.2161)$ & $(0.2219)$ & $(0.2658)$ & $(0.2932)$ \\
\hline \multirow[t]{2}{*}{ Head's educ. years } & & $0.0307^{* * *}$ & 0.0108 & -0.0122 & 0.0027 \\
\hline & & $(0.0076)$ & $(0.0074)$ & $(0.0091)$ & $(0.011)$ \\
\hline \multirow[t]{2}{*}{ Adult females } & & $0.1499^{* * *}$ & $0.1236^{* * *}$ & $0.1582^{* * *}$ & 0.0381 \\
\hline & & $(0.0471)$ & $(0.0464)$ & $(0.0521)$ & $(0.0664)$ \\
\hline \multirow[t]{2}{*}{ Adult males } & & 0.0633 & 0.0529 & $0.0843^{*}$ & 0.0267 \\
\hline & & $(0.0442)$ & $(0.0434)$ & $(0.0494)$ & $(0.0648)$ \\
\hline \multirow[t]{2}{*}{ Dependents } & & $0.0505^{* * *}$ & $0.0565^{* * *}$ & 0.0001 & $0.0506^{* *}$ \\
\hline & & $(0.0167)$ & $(0.0165)$ & $(0.019)$ & $(0.0235)$ \\
\hline \multirow[t]{2}{*}{ Urban } & & $0.2171^{*}$ & $0.2698^{* *}$ & $-0.2718^{*}$ & -0.1802 \\
\hline & & $(0.1214)$ & $(0.1189)$ & $(0.1584)$ & $(0.2042)$ \\
\hline \multirow[t]{2}{*}{ Rainfall shock } & & $-1.0998^{* * *}$ & $-1.0595^{* * *}$ & -0.4516 & -0.1658 \\
\hline & & $(0.2954)$ & $(0.293)$ & $(0.3311)$ & $(0.3828)$ \\
\hline \multirow[t]{2}{*}{ Infrastructural index } & & $-0.1157^{* * *}$ & $-0.1199^{* * *}$ & 0.0333 & 0.0517 \\
\hline & & $(0.034)$ & $(0.034)$ & $(0.0382)$ & $(0.0499)$ \\
\hline \multirow[t]{2}{*}{ There is a bus stop in village? } & & $0.2217^{* * *}$ & $0.1495^{*}$ & 0.0303 & 0.1582 \\
\hline & & $(0.0817)$ & $(0.0806)$ & $(0.0883)$ & $(0.1)$ \\
\hline \multirow[t]{2}{*}{ Constant } & & $-1.5093^{* * *}$ & $-1.4585^{* * *}$ & $-1.4732^{* * *}$ & $-1.9228^{* *}$ \\
\hline & & $(0.2777)$ & $(0.2833)$ & $(0.3477)$ & $(0.8586)$ \\
\hline \multirow[t]{2}{*}{$\rho$} & & $0.2952^{* * *}$ & $0.2967^{* * *}$ & $0.4179^{* * *}$ & $0.4992^{* * *}$ \\
\hline & & $(0.0518)$ & $(0.0521)$ & $(0.0608)$ & $(0.0608)$ \\
\hline State FE & & Yes & Yes & Yes & Yes \\
\hline Observations & & 2,727 & 2,727 & 2,727 & 2,727 \\
\hline
\end{tabular}

Standard errors in parentheses. Spatial probit: 8,004 draws, 1,992 burn-in $\left({ }^{* * *} \mathrm{p}<0.01,{ }^{* *} \mathrm{p}<0.05,{ }^{*} \mathrm{p}<0.1\right)$

a) Non-farm enterprise; b) Cash cropping 
Table 11: diversification by activity, SAR probit estimates, South

Nigeria-South

\begin{tabular}{|c|c|c|c|c|c|}
\hline \multirow[b]{2}{*}{ Variables } & \multicolumn{3}{|c|}{ Non-farm diversification } & \multicolumn{2}{|c|}{ Farm diversification } \\
\hline & $N F E^{a}$ & E Non-farm Wage & $N F E^{a}$ & Comm.crop ${ }^{b}$ \& Farm Wage & Comm.crop ${ }^{b}$ \\
\hline \multirow[t]{2}{*}{ Nat. $\log$ of hectares owned } & & -0.055 & -0.026 & $0.1323^{* * *}$ & $0.2134^{* * *}$ \\
\hline & & $(0.0342)$ & $(0.0341)$ & $(0.0395)$ & $(0.0453)$ \\
\hline \multirow[t]{2}{*}{ Female headed } & & 0.0553 & 0.0676 & 0.0745 & 0.069 \\
\hline & & $(0.1803)$ & $(0.1792)$ & $(0.2009)$ & $(0.222)$ \\
\hline \multirow[t]{2}{*}{ Head's age } & & $-0.0169^{* * *}$ & $-0.0181^{* * *}$ & 0.0034 & 0.0056 \\
\hline & & $(0.0035)$ & $(0.0035)$ & $(0.0038)$ & $(0.0043)$ \\
\hline \multirow[t]{2}{*}{ Head is married } & & $0.3897^{* *}$ & $0.4108^{* *}$ & 0.1748 & 0.1799 \\
\hline & & $(0.1633)$ & $(0.1628)$ & $(0.184)$ & $(0.2074)$ \\
\hline \multirow[t]{2}{*}{ Head's educ. years } & & $0.0184^{*}$ & 0.0015 & 0.0157 & 0.021 \\
\hline & & $(0.0103)$ & $(0.0103)$ & $(0.0117)$ & $(0.0132)$ \\
\hline \multirow[t]{2}{*}{ Adult females } & & $0.1681^{* * *}$ & $0.1438^{* * *}$ & -0.0024 & 0.0057 \\
\hline & & $(0.0455)$ & $(0.0451)$ & $(0.0517)$ & $(0.0603)$ \\
\hline \multirow[t]{2}{*}{ Adult males } & & $0.194^{* * *}$ & $0.1093^{* *}$ & -0.0196 & $-0.144^{*}$ \\
\hline & & $(0.051)$ & $(0.0499)$ & $(0.0573)$ & $(0.0742)$ \\
\hline \multirow[t]{2}{*}{ Dependents } & & 0.0315 & 0.0253 & -0.0077 & -0.03 \\
\hline & & $(0.0255)$ & $(0.0252)$ & $(0.0285)$ & $(0.0329)$ \\
\hline \multirow[t]{2}{*}{ Urban } & & $0.2992^{* *}$ & $0.2715^{* *}$ & 0.0073 & -0.0708 \\
\hline & & $(0.1346)$ & $(0.1296)$ & $(0.1295)$ & $(0.1395)$ \\
\hline \multirow[t]{2}{*}{ Rainfall shock } & & $-1.4635^{* *}$ & $-1.6394^{* *}$ & $-1.4628^{* *}$ & -0.9902 \\
\hline & & $(0.6561)$ & $(0.6495)$ & $(0.6616)$ & $(0.6853)$ \\
\hline \multirow[t]{2}{*}{ Infrastructural index } & & $-0.3314^{* * *}$ & $-0.3001^{* * *}$ & -0.0057 & 0.0385 \\
\hline & & $(0.1127)$ & $(0.1112)$ & $(0.1181)$ & $(0.1323)$ \\
\hline \multirow[t]{2}{*}{ There is a bus stop in village? } & & 0.0917 & 0.1636 & $-0.2872^{* *}$ & $-0.258^{* *}$ \\
\hline & & $(0.1166)$ & $(0.1153)$ & $(0.1208)$ & $(0.1314)$ \\
\hline \multirow[t]{2}{*}{ Constant } & & $-1.101^{* * *}$ & $-0.956^{* *}$ & $-1.3523^{* * *}$ & $-0.9095^{* *}$ \\
\hline & & $(0.3848)$ & $(0.384)$ & $(0.427)$ & $(0.4595)$ \\
\hline \multirow[t]{2}{*}{$\rho$} & & -0.0499 & -0.0332 & $0.1837^{* *}$ & $0.2803^{* * *}$ \\
\hline & & $(0.087)$ & $(0.0869)$ & $(0.0869)$ & $(0.0873)$ \\
\hline State FE & & Yes & Yes & Yes & Yes \\
\hline Observations & & 2,727 & 2,727 & 2,727 & 2,727 \\
\hline
\end{tabular}

Standard errors in parentheses. Spatial probit: 8,004 draws, 1,992 burn-in $\left(* * * \mathrm{p}<0.01,{ }^{* *} \mathrm{p}<0.05,{ }^{*} \mathrm{p}<0.1\right.$ )

a) Non-farm enterprise; b) Cash cropping 
Table B.2: diversification by activity, SAR probit estimates, Marginal Effects, South

South

\begin{tabular}{|c|c|c|c|c|c|c|}
\hline Variables & Comm. crop (direct) & Comm. crop (indirect) & Comm. crop (total) & Comm. \&s Farm wage (direct) & Comm. \&s Farm wage(indirect) & Comm. \& Farm wage(total) \\
\hline \multirow[t]{2}{*}{ Nat. $\log$ of hectares owned } & 0.0400092 & 0.01424 & 0.054246 & 0.0314317 & 0.00706 & 0.0384917 \\
\hline & {$[0.0256008,0.056]$} & {$[0.004615,0.027]$} & {$[0.033914,0.079]$} & {$[0.015269,0.049]$} & {$[0.0008694,0.015]$} & {$[0.0183515,0.06]$} \\
\hline \multirow[t]{2}{*}{ Female headed } & 0.0190269 & 0.006941 & 0.0259683 & 0.023883 & 0.0055632 & 0.0294462 \\
\hline & {$[-0.046735,0.087]$} & {$[-0.01646,0.035]$} & {$[-0.0643358,0.12]$} & {$[-0.0537238,0.103]$} & {$[-0.0119602,0.028]$} & {$[-0.0640192,0.128]$} \\
\hline \multirow[t]{2}{*}{ Head's age } & 0.0010118 & 0.0003617 & 0.0013735 & 0.0007542 & 0.0001736 & 0.0009277 \\
\hline & {$[-0.0003748,0.002]$} & {$[-0.0001172,0.001]$} & {$[-0.0005084,0.003]$} & {$[-0.0007705,0.002]$} & {$[-0.0001436,0.001]$} & {$[-0.0008864,0.003]$} \\
\hline \multirow[t]{2}{*}{ Head is married } & 0.0390825 & 0.01354 & 0.0526218 & 0.0467268 & 0.0103668 & 0.0570937 \\
\hline & {$[-0.0267977,0.108]$} & {$[-0.009875,0.043]$} & {$[-0.0367434,0.149]$} & {$[-0.0272669,0.126]$} & {$[-0.0067006,0.035]$} & {$[-0.0340422,0.155]$} \\
\hline \multirow[t]{2}{*}{ Head's educ. years } & 0.003703 & 0.001336 & 0.0050387 & 0.003492 & 0.0008024 & 0.0042944 \\
\hline & {$[-0.0005235,0.008]$} & {$[-0.0001753,0.003]$} & {$[-0.0007351,0.011]$} & {$[-0.0013602,0.008]$} & {$[-0.0002285,0.002]$} & {$[-0.0015861,0.01]$} \\
\hline \multirow[t]{2}{*}{ Adult females } & 0.0001168 & 0.00008311 & 0.0002 & -0.0013389 & -0.0001789 & -0.0015178 \\
\hline & {$[-0.0177046,0.019]$} & {$[-0.007037,0.007]$} & {$[-0.025183,0.027]$} & {$[-0.023257,0.02]$} & {$[-0.0055933,0.006]$} & {$[-0.02649,0.025]$} \\
\hline \multirow[t]{2}{*}{ Adult males } & -0.0262982 & -0.009177 & -0.0354756 & -0.0032438 & -0.0006042 & -0.003848 \\
\hline & {$[-0.0496243,-0.004]$} & {$[-0.02165,-0.001]$} & {$[-0.0682018,-0.005]$} & {$[-0.025476,0.019]$} & {$[-0.0064758,0.005]$} & {$[-0.0317884,0.022]$} \\
\hline \multirow[t]{2}{*}{ Dependents } & -0.0058081 & -0.002007 & -0.0078153 & -0.0019888 & -0.0004106 & -0.0023994 \\
\hline & {$[-0.0168656,0.004]$} & {$[-0.006945,0.001]$} & {$[-0.0230931,0.005]$} & {$[-0.013846,0.009]$} & {$[-0.0034307,0.002]$} & {$[-0.0173686,0.011]$} \\
\hline \multirow[t]{2}{*}{ Urban } & -0.0141239 & -0.004731 & -0.0188547 & 0.0012226 & 0.0005161 & 0.0017387 \\
\hline & {$[-0.0579938,0.028]$} & {$[-0.0218,0.01]$} & {$[-0.077182,0.038]$} & {$[-0.0496963,0.051]$} & {$[-0.0121955,0.014]$} & {$[-0.0598388,0.063]$} \\
\hline \multirow[t]{2}{*}{ Rainfall shock } & -0.1974605 & -0.06746 & -0.2649246 & -0.3636411 & -0.0790739 & -0.442715 \\
\hline & {$[-0.4092956,0.023]$} & {$[-0.1628,0.008]$} & {$[-0.5454584,0.031]$} & {$[-0.6302729,-0.088]$} & {$[-0.1763894,-0.006]$} & {$[-0.7555222,-0.111]$} \\
\hline \multirow[t]{2}{*}{ Infrastructural constraint } & 0.0057645 & 0.001695 & 0.0074595 & -0.0024172 & -0.0008667 & -0.003284 \\
\hline & {$[-0.0387476,0.048]$} & {$[-0.01461,0.016]$} & {$[-0.0534352,0.064]$} & {$[-0.0537413,0.047]$} & {$[-0.0134592,0.01]$} & {$[-0.0638964,0.055]$} \\
\hline \multirow[t]{2}{*}{ There is a bus stop in village? } & -0.0477923 & -0.01678 & -0.0645684 & -0.0674249 & -0.0150615 & -0.0824864 \\
\hline & {$[-0.0867417,-0.009]$} & {$[-0.03634,-0.002]$} & {$[-0.1184954,-0.012]$} & {$[-0.1155098,-0.021]$} & {$[-0.0343856,-0.001]$} & {$[-0.1396733,-0.025]$} \\
\hline State FE & Yes & Yes & Yes & Yes & Yes & Yes \\
\hline Observations & 2,727 & 2,727 & 2,727 & 2,727 & 2,727 & 2,727 \\
\hline
\end{tabular}

$95 \%$ confidence interval estimates in brackets 


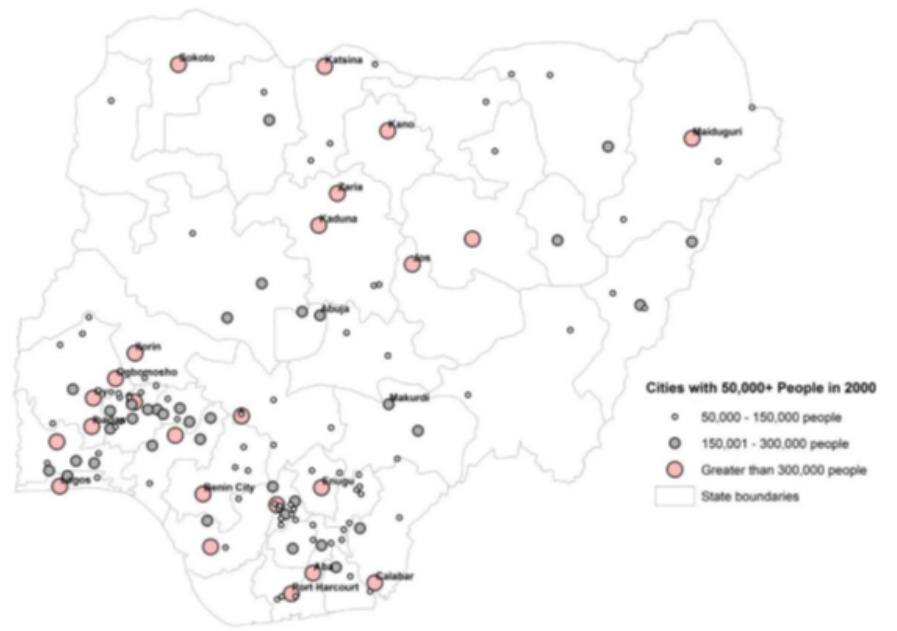

Figure 1: Urbanization by cities size. Source: Bloch et al. (2015)

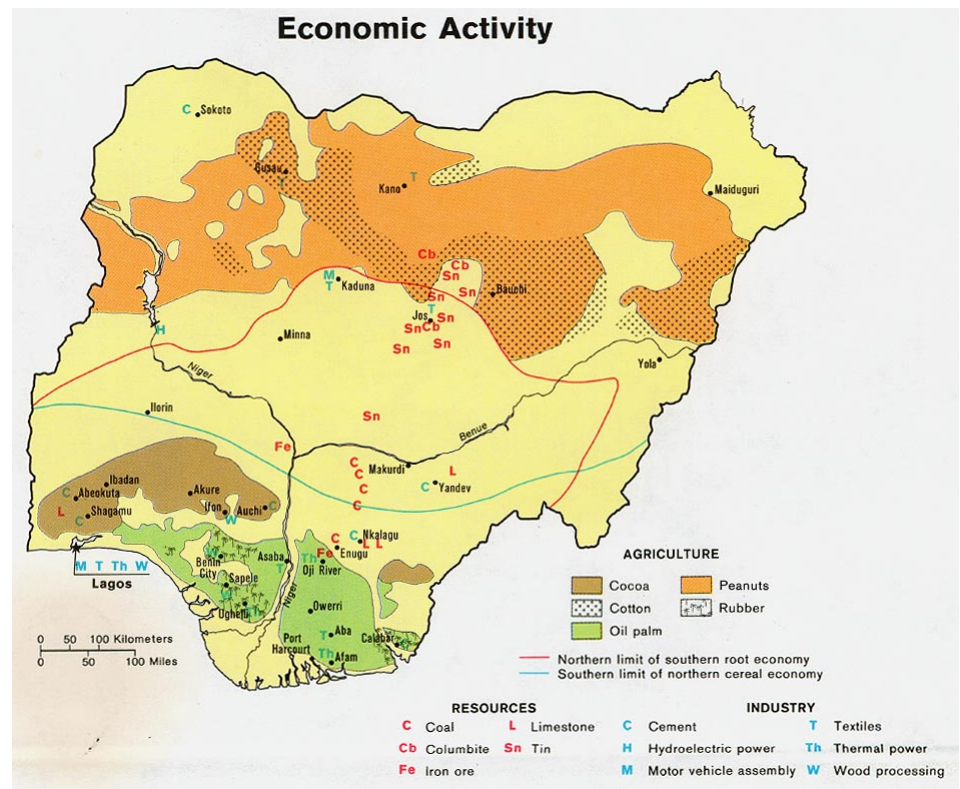

Figure 2: Nigerian Economic Activity. Source: Aregheore (2009). 


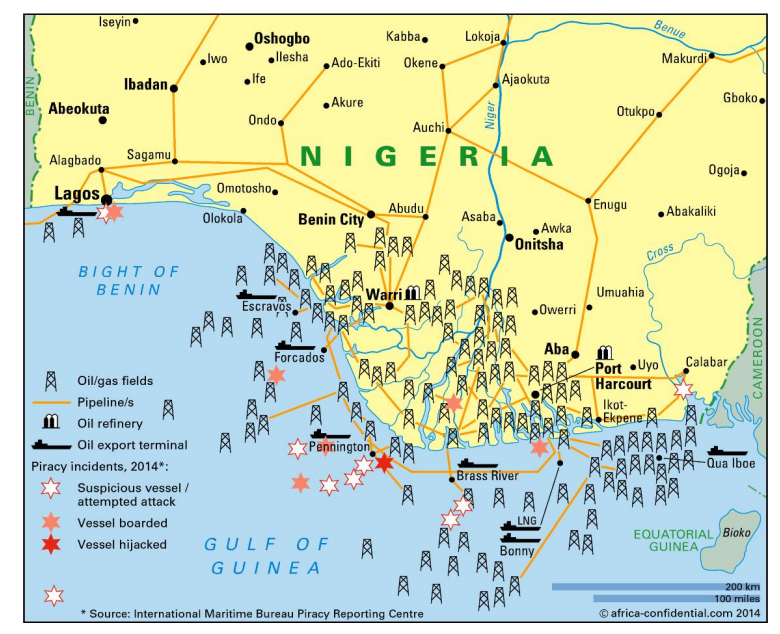

Figure 3: Nigerian oil industry. Source: International Maritime Bureau Piracy Reporting Center, 2014

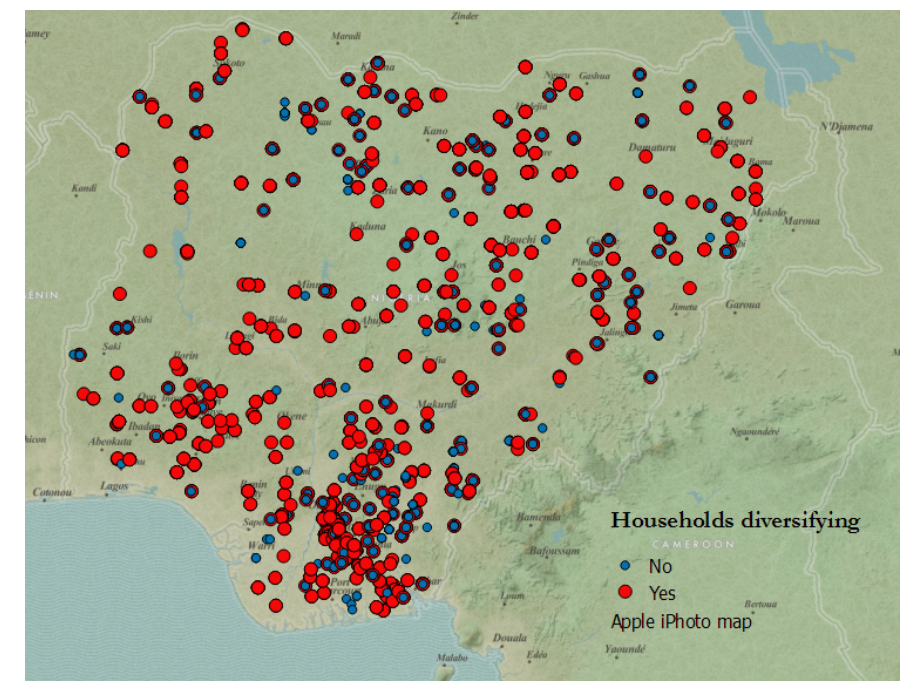

Figure 4: Diversifying and non-diversifying households 


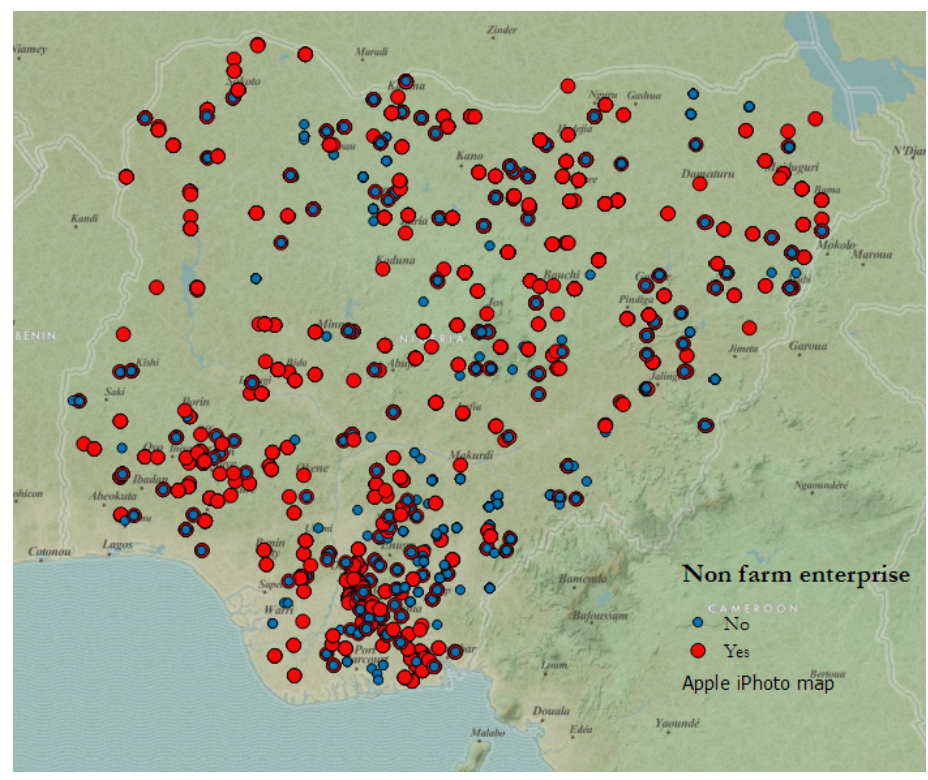

Figure 5: Diversification by NFE

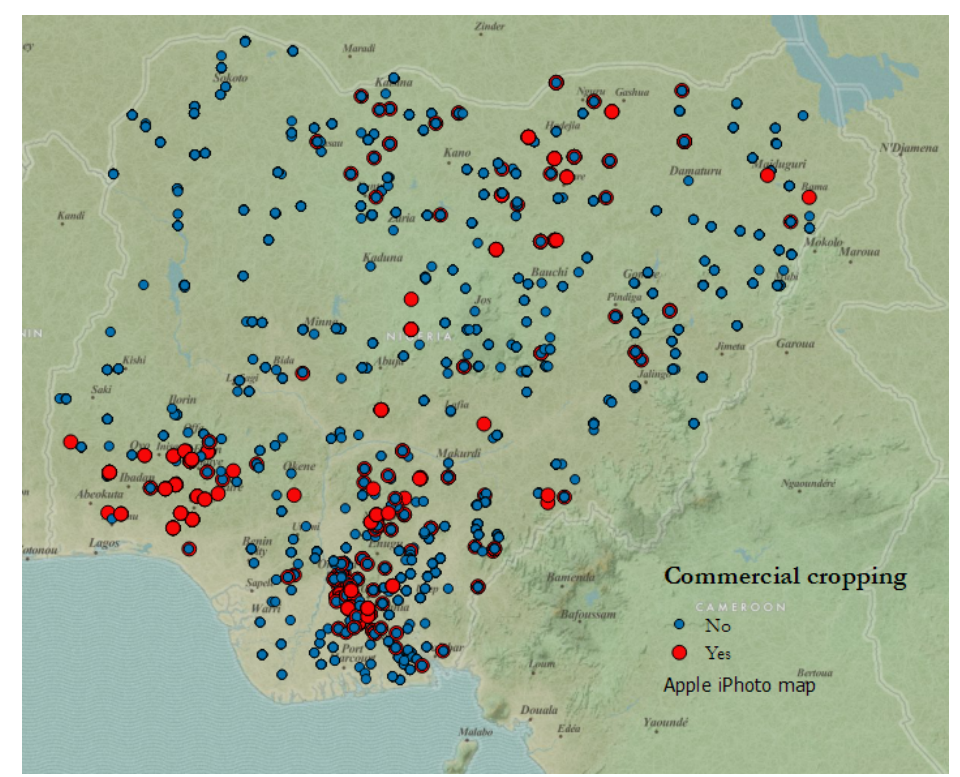

Figure 6: Diversification by cash cropping 


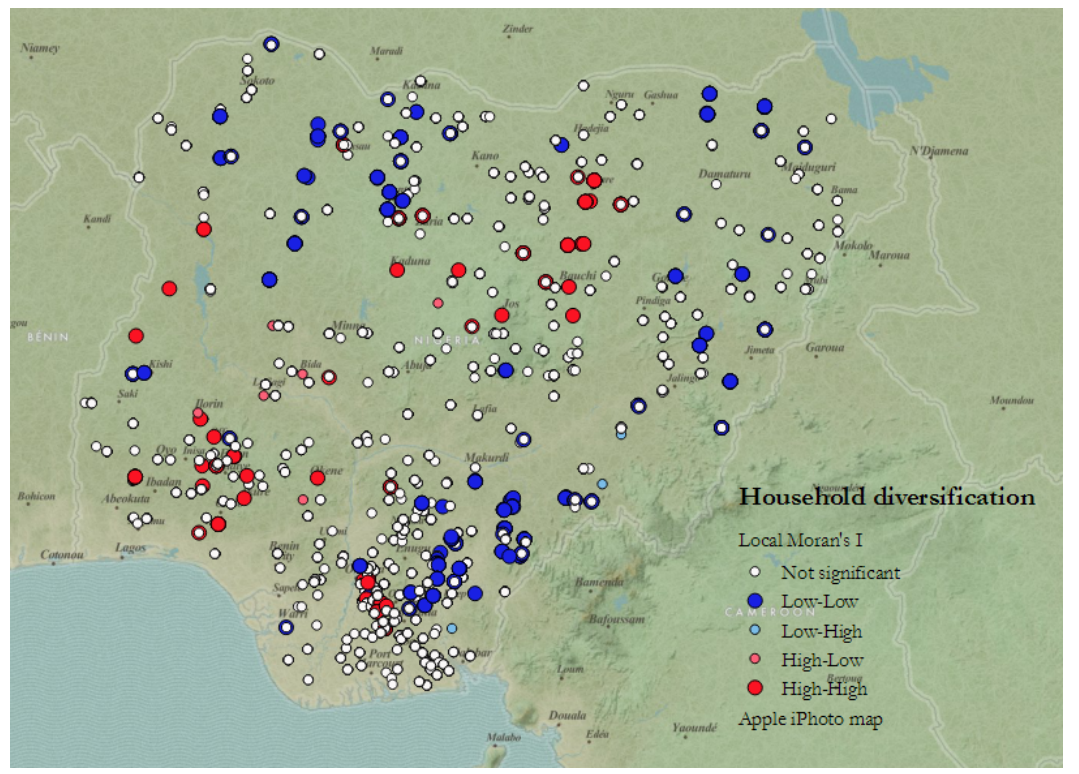

Figure 7: Diversification: spatial autocorrelation, LISA output

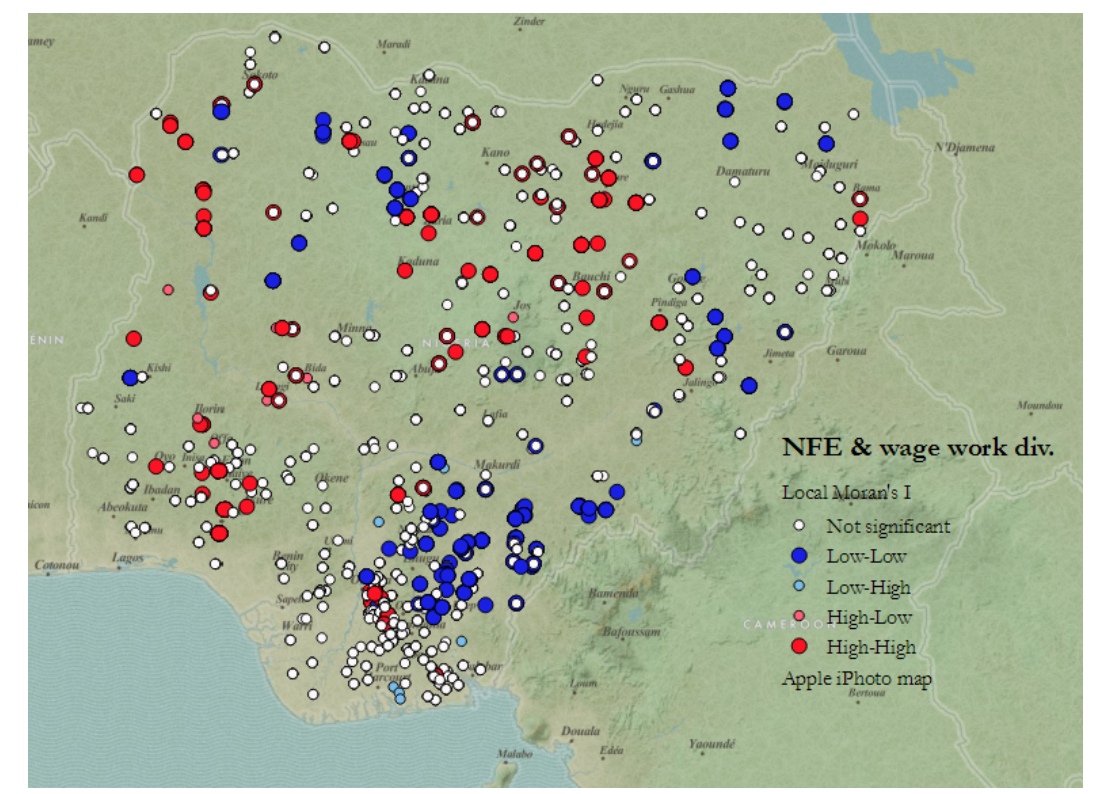

Figure 8: Non-farm diversification: spatial autocorrelation, LISA output 


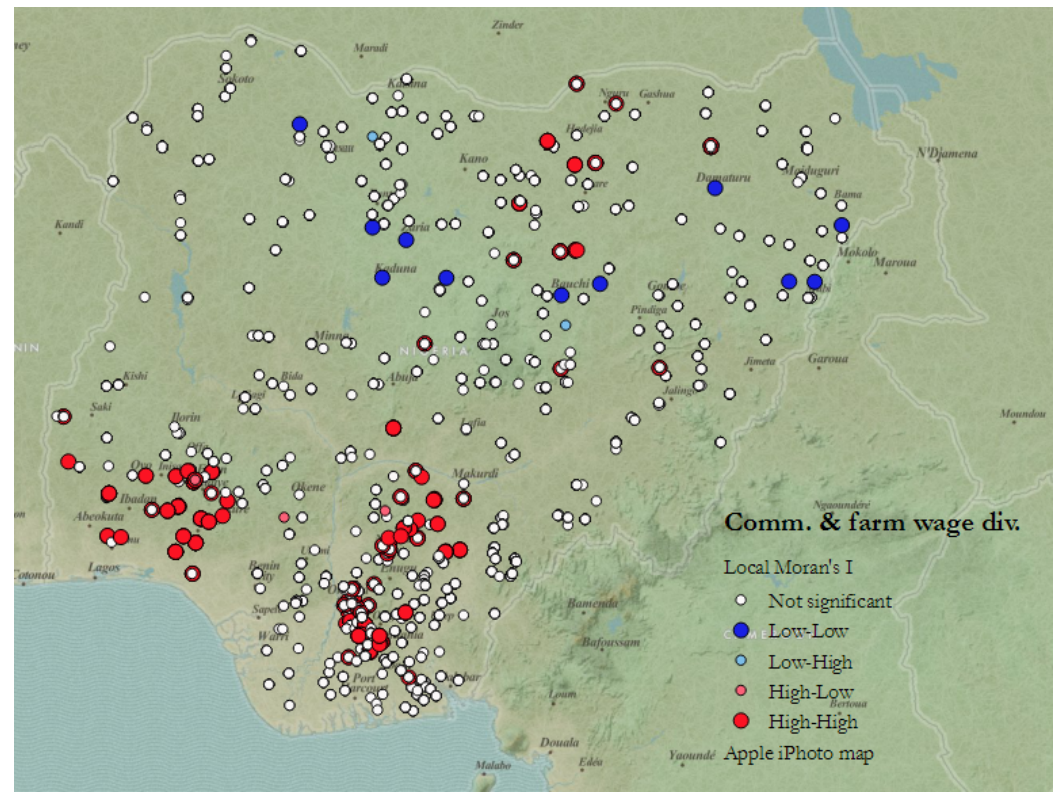

Figure 9: Farm diversification: spatial autocorrelation, LISA output

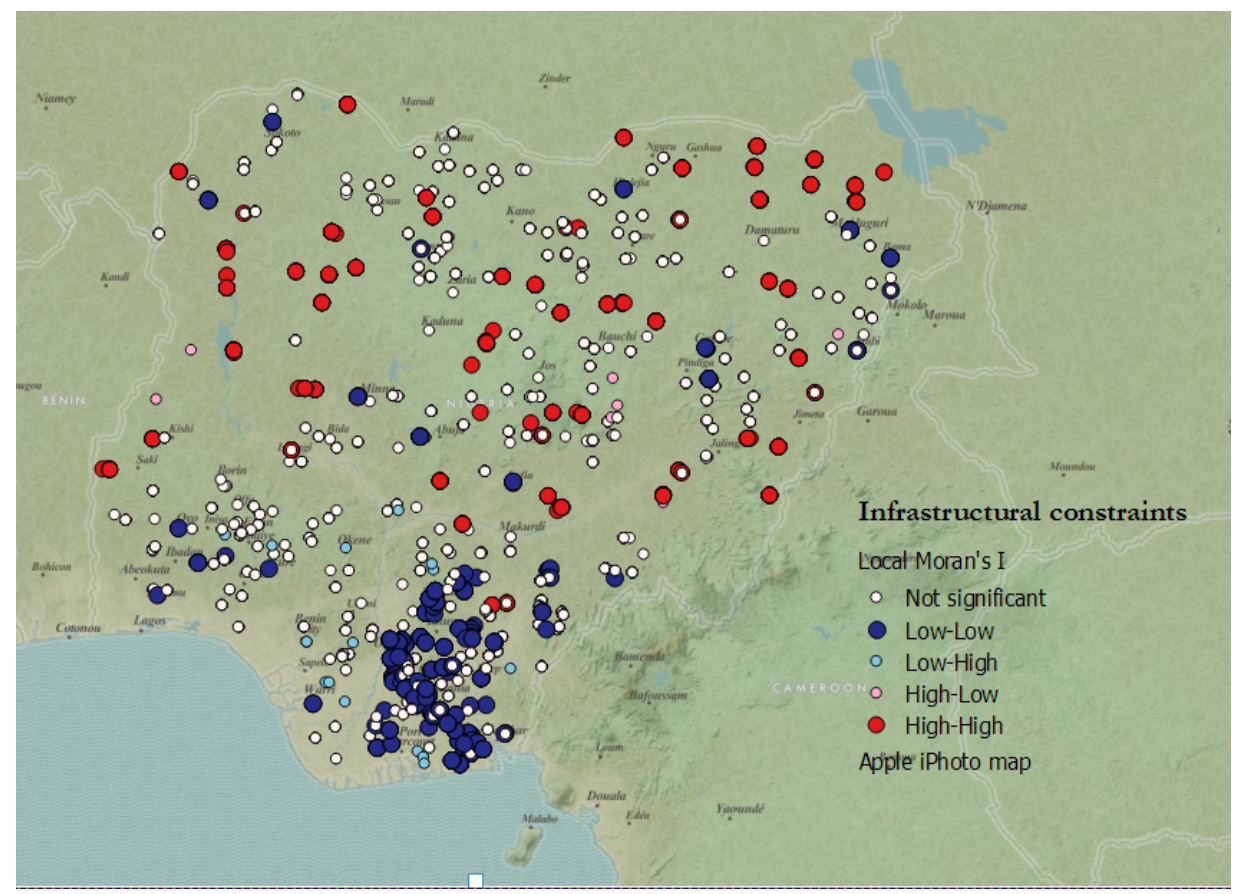

Figure 10: Infrastructural constraints: spatial autocorrelation, LISA output 


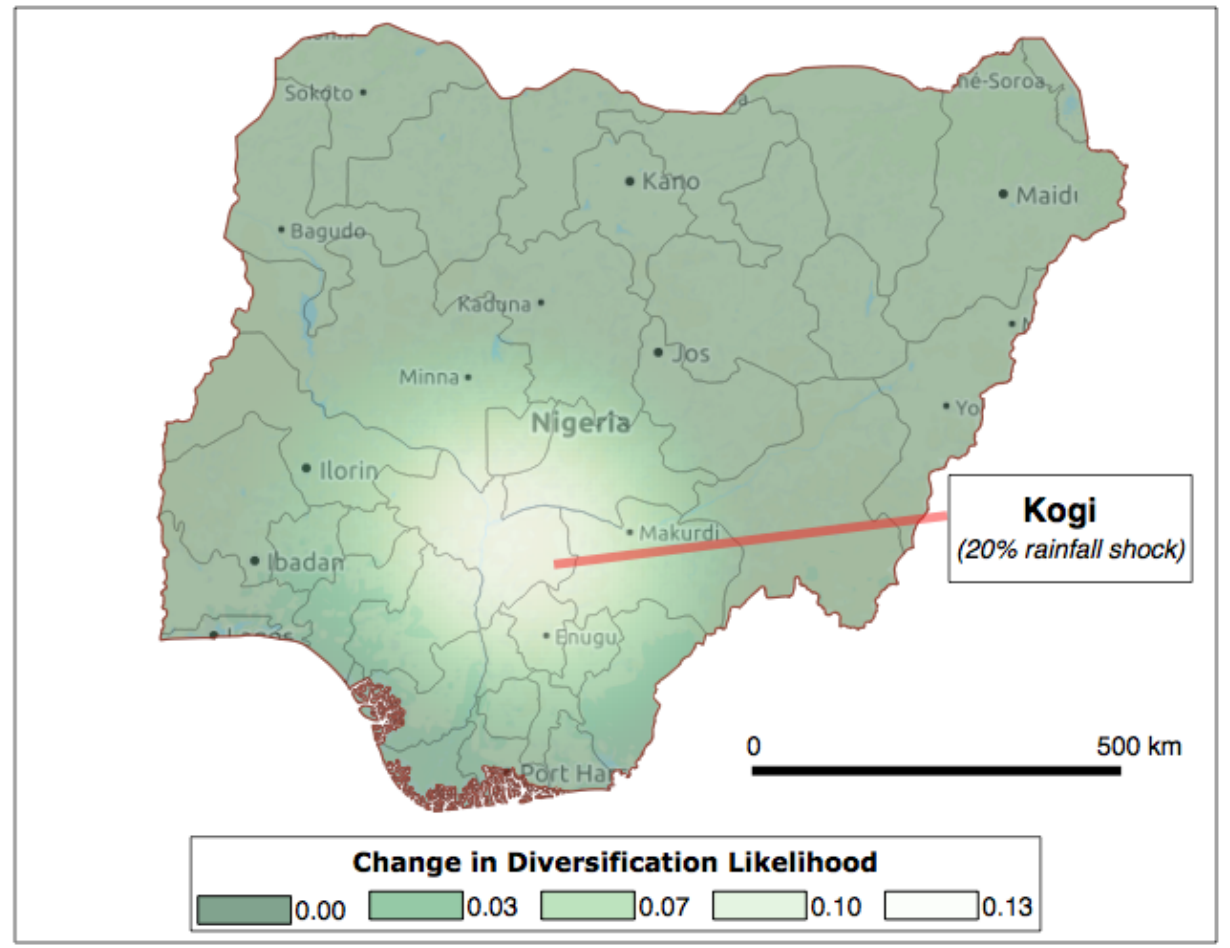

Figure 11: Spillover effect of a negative rainfall shock in Kogi 